\title{
A Pinch-based method for defining pressure manipulation routes in work and heat
} exchange networks

\author{
Leandro V. Pavão ${ }^{a 1}$, José A. Caballero $^{b}$, Mauro A. S. S. Ravagnani ${ }^{a}$, Caliane B. B. Costa ${ }^{a}$
} ${ }^{a}$ Department of Chemical Engineering, State University of Maringá, Av. Colombo, 5790, Bloco D90, CEP 87020900, Maringá, PR, Brazil

binstitute of Chemical Process Engineering, University of Alicante, Ap. Correos 99, 03080 Alicante, Spain

\begin{abstract}
Academic attention to work and heat integration (WHI) has grown in the last decade. Simultaneous models for work and heat exchanger network (WHEN) synthesis often derive from heat integration (HI) frameworks. However, it can be noted that the solution of simultaneous optimization models for WHI is considerably more complex than in the HI case. The design of efficient pressure manipulation routes (i.e., allocation and sizing of compression and expansion machinery) in process streams prior to heat exchange match allocation can make the optimization procedure more efficient. This work proposes a systematic procedure based on a model that employs Pinch Analysis concepts for defining these routes based on capital and operating cost targets. The solution approach is a hybrid meta-heuristic method based on Simulated Annealing (SA) and Particle Swarm Optimization (PSO). The obtained routes are then converted into a HI problem by fixing pressure changer sizes. The detailed HI solution is finally transferred into a WHI optimization model as initial design. In the two tackled examples, the total annual costs (TAC) predicted by the Pinch-based model differed in $0.5 \%$ and $1.2 \%$ from the final optimized WHEN obtained in the detailed WHI framework.
\end{abstract}

Keywords: Optimization; Work and Heat Integration; Work and Heat Exchange Networks; Pinch Analysis; Meta-heuristics; Process Synthesis

\section{Introduction}

Under a constant scenario of growth in energy needs in industry, academic interest in simultaneous work and heat integration is increasing. Work and heat integration (WHI) can be thought of analogously to pure heat integration (HI). The latter is a well-studied topic, whose main subject is solving the following problem: given a set of process material streams with supply and target temperatures, allocate a set of equipment able to lead those streams to target conditions either via energy exchange among themselves or via external utilities. The apparatus used for

\footnotetext{
${ }^{1}$ Corresponding author. Tel: +55 (44) 3011-4774, Fax: +55 (44) 3011-4793

E-mail address: leandropavao@gmail.com
} 
performing the aforementioned energy exchange are the well-known heat exchangers, and the described problem is called synthesis of heat exchanger networks (HEN). Conversely, the work exchange network (WEN) synthesis problem consists of using some sort of machinery analogous to heat exchangers able to transfer work from high-pressure stream to low-pressure ones, saving electricity required for compression. By extension, work and heat exchange network (WHEN) synthesis consists in solving an energy exchange problem with streams that require temperature and/or pressure changes.

Although different device concepts have been developed and applied in industry for work recovery, it has been only recently that WHEN synthesis has become a trend in process synthesis. On the other hand, HEN synthesis studies have constantly evolved and been published for over 40 years. Some landmark studies on the topic are those related to Pinch technology, which was pioneered by Linnhoff and co-workers: targets for heat recovery [1] and well-established heuristics [2] were developed for the systematic synthesis of HEN. Later studies involved targets for heat exchange area as well [3]. An extensive review on Pinch technology was published by Klemeš and Kravanja [4], and a more recent review by Klemeš et al. [5] presents future directions for the scope. The reader is also referred to the Pinch technology extended key book [6], which is an instructive support material on the topic.

As computing technologies advanced, mathematical programming models were developed on the heat integration topic. Papoulias and Grossmann [7] were able to reproduce the algorithmic procedures of energy targeting from Pinch analysis by means of a linear programming (LP) model. Area targeting was translated into a mathematical model by Colberg and Morari [8]. A sequential model for HEN synthesis involving targeting and sizing was developed by Floudas et al. [9]. Prominent simultaneous mixed-integer nonlinear programming (MINLP) models for onestep HEN synthesis were presented by Floudas and Ciric [10], which was an extensive model comprising several structural options such as splitting, sub-splitting, and stream crossflows, and by Yee and Grossmann [11], which was structurally simpler, comprising only stream splits with isothermal mixing assumption, but was also less complex to solve, leading to efficient solutions. Concepts developed in these simultaneous models serve as basis to recent efforts in automated HEN synthesis, such as the stagewise superstructure with sub streams, substages and crossflows [12], the stageless superstructure [13] and the non-structural model [14].

Work exchange machinery are well-established in industry, for instance in desalination industry [15] or power recovery trains of fluid catalytic cracking plants [16]. However, discussions on WEN and WHEN synthesis are more recent. The widely studied approaches for HEN synthesis certainly provided valuable insights for the newer WEN and WHEN synthesis trends. The work of Huang and Fan [17] proposed pressure-work diagrams analogous to temperature-enthalpy diagrams from Pinch analysis, and applied direct work exchanger units [18] in WEN synthesis. This sort of unit consists in vessels with a floating piston head. In it, a high-pressure fluid 
compresses a low-pressure one. These units were also considered in the WEN synthesis graphical method of Zhuang et al. [19]. Work may as well be indirectly exchanged by conversion to electricity in turbine generators, being converted back into shaft-work in compressors, or by single-shaft-turbine-compressor (SSTC) couplings. Some contributions in the sense of developing methodologies for obtaining optimal pressure change routes minimizing energy consumption in sets of high and low-pressure (HP and LP) streams can be highlighted here. Aspelund et al. [20] used Pinch Analysis concepts for developing the Extend Pinch Analysis and Design (ExPAnD) method. They presented important insights on the heuristic development of optimal pressure change with minimal energy consumption for sub-ambient processes. Wechsung et al. [21] developed a superstructure where a stream could pass multiple times through a heat recovery region. The methodology involved Pinch and exergy analysis with mathematical programming for reducing process irreversibility. Razib et al. [22] presented a superstructure-based mathematical programming model for synthesizing WEN using SSTC units. Onishi et al. [23] presented a superstructure based on the concept of multiple passes concept through a heat recovery region [21], but replacing the Pinch operator of that region with the stagewise superstructure (SWS) [11] and minimizing total annual costs (TAC) rather than process irreversibility. The possible pressure change routes considered in the superstructure were those defined by Wechsung et al. [21]. A mathematical model was then derived for an automated allocation of pressure changers simultaneously to HEN synthesis. Onishi et al. [24] later improved their superstructure considering stream splits in the work recovery region and multiple shafts for turbine-compressor coupling. A framework for WHEN retrofit was presented by Onishi et al. [25] based on their previous model [23]. Huang and Karimi [26] presented a framework for WHEN synthesis extending the WEN formulation of Razib et al. [22] including a HEN stage between WEN stages. Fu and Gundersen [27] presented a set of theorems for the correct integration of compressors and expanders into above ambient heat exchanger networks aiming at minimization of exergy consumption. Those authors later applied these techniques to case studies in carbon dioxide capture processes [28]. Pavão et al. [29] presented a meta-heuristic based approach for WHEN synthesis considering multiple passes through a heat recovery region. The method used a coupling matrix to link the work exchange region of the model to the enhanced SWS [30] used for the heat recovery stage and was later extended to handle multiple scenarios related to electricity cost variations [31]. The pressure change routes in those works [29,31] were fixed following Wechsung et al. [21] insights. Nair et al. [32] developed a model comprising streams with phase change and without pre-identifying streams as hot, cold, HP or LP, which were defined via optimization. Additionally, the interested reader can find reviews on WHI including possible opportunities and challenges in the works of Fu et al. [33] and Yu et al. [34].

The simultaneous integration of work and heat has some interesting intricacies. The problem may be thought as a heat integration problem with variable temperatures, as well as additional energy 
balances and costs-related variables for pressure changers. Modifications in pressure manipulation routes (i.e., number, types and sizes of pressure changers) lead to temperature changes and therefore in heat availability/requirement, which may greatly affect the heat integration process. This may hinder the development of heuristic procedures for WHI given that some options for energy exchange may not be as intuitive as in pure HEN synthesis. Therefore mathematical programming seems to be the most viable option [35]. However, with the additional variables and non-linear constraints, it may be a great advantage if a promising pressure change structure, operating in efficient temperature ranges for low shaft-work usage and high shaft-work generation, is selected as an initial estimate in solving these simultaneous models.

It can be noted that frameworks for correct allocation of compressors and turbines often use exergy-based concepts, and have proven to reduce process irreversibility. This work proposes to identify such an optimal structure prior to effectively synthesizing a WHEN by using Pinch concepts and focusing on total annual costs (TAC) targeting for a WHEN prior to its heat exchange units detailed allocation and sizing.

Consider the following ideal sequential procedure, which would be able to find the optimal pressure change route: (i) enter new pressure change route configuration; (ii) find globally optimal heat integration structure for that route; (iii) check if total annual costs improved and record solution in that case; (iv) go back to (i). The procedure is repeated until all possible routes are evaluated. It is evident that such a procedure is infeasible with current computing technologies. These routes involve not only defining what pressure changer sequence is to be used in each process stream, but also the degree of compression/expansion performed by each apparatus (i.e., a problem involving combinatorial and continuous optimization with infinite solutions). Moreover, globally optimal heat integration (step (ii)) considering a large number of streams is currently an unsolvable problem per se [36], having a very large number of associated variables, nonlinear constraints and nonconvexities.

The aforementioned algorithm is not useless though. It must be thought of as an ideal, hypothetical computing method, from which we can draw some inspiration in order to develop a feasible method. The present proposal takes some insight from such an idealized scheme. The idea is to use targeting concepts from Pinch technology, which are deterministic, fast to compute procedures, for replacing the global optimal heat integration step of the aforementioned ideal methodology. Steps (i), (iii) and (iv) are replaced by a hybrid meta-heuristic method based on Simulated Annealing [37] and Particle Swarm Optimization [38], which defines modifications to the pressure change route, acceptance and termination criteria. These stochastic methods rely on some degree of randomness and extensive objective function re-evaluations to guide solutions towards lower-cost options.

The referred Pinch-based concepts to be used here are minimum utility and heat exchange area targeting. Capital and operating costs may be associated to these targets. In fact, according to 
Linnhoff and Ahmad [3], TAC of detailed HENs synthesized by the authors after the targeting procedures were found to be within 5\% of the optimized TAC via targeting. Therefore, we attempt to find an optimal pressure change route that leads to an optimal capital and operating costs target. Moreover, for work exchange targeting we consider all compressors and turbines to be coupled while a helper motor or generator may be used in case of shaft-work lack or surplus. Several experiments are proposed to validate the method, such as the identification of optimal routes considering or not capital cost targets or considering temperature manipulation via utilities only. Different sets of decision variables are tested as well, such as inlet/discharge temperatures and pressure ratios. These routes are input into detailed HEN and detailed WHEN models in order to find and compare final configurations according to their total annual costs.

It should be noted that, due to the possible number of structural combinations and inherent nonlinearities, the synthesis of heat and work integration structures via a simultaneous procedure is complex. This greatly hampers the development of derived models considering, for instance, multiple objectives or uncertain parameters. Hence, we aim to contribute to the field by proposing a simplified targeting model for early design stages and whose predicted cost results differ little from those of final detailed WHEN designs.

\subsection{Problem statement}

A set of streams that can be classified according to supply and target pressure and temperature conditions is given. Pressure manipulation routes must be found for all these streams in order for them to reach target pressures. This involves defining the number of compressors/turbines applied to perform a given pressure change, as well as the operating temperature ranges of these units. For operating within these temperature ranges, heat may be provided/removed from streams via heat exchange among themselves or via heaters/coolers using external utilities. Heat exchange or utility-based temperature manipulation may be used as well for streams to reach pre-defined target temperatures. Therefore, an optimal heat integration structure is required.

All compressor/turbines can be coupled via SSTC for work exchange. Shaft-work shortage are provided via helper motor, while shaft-work surplus is converted into electricity via helper generator and sold to the grid.

Heat capacity flowrates and convective heat transfer coefficients for all streams are known constants. Isentropic efficiencies and polytropic exponents for compressors/turbines are known constants. HP and LP streams are ideal gases.

\section{Work and heat integration framework}

The work and heat integration model developed in this work takes as basis the idea of a stream being able to pass multiple times through a heat recovery region, with pressure manipulation between these passes (Figure 1a). It is worth noting that the simultaneous identification of an 
optimal structure able to efficiently exchange work and heat is a difficult task. Individually, the heat recovery region can be seen as a HEN synthesis problem. In varying the number and sizes of pressure changers, the number of streams in that HEN problem, as well as their supply and target temperatures, varies as well. This leads to the requirement of topology and sizing modifications to the HEN in order for it to reach optimal costs. However, the synthesis of a HEN per se is not a simple task. It is, in fact, classified as an NP-hard problem [36]. Therefore, instead of simultaneously attempting to design optimal pressure changing routes with detailed heat recovery configuration, a different approach is developed here. Pinch analysis $[1,2]$ and derived methods are able to provide targets for utilities consumption as well as predictions for minimal heat exchange area [3] without needing to identify a rigorous HEN design (i.e., with all matches and heat exchanger sizes). Operating and capital costs (OC and CC) may be associated to these predicted design aspects, and a minimization problem can provide a good total annual cost (TAC) target for a subsequent detailed HEN/WHEN design.

Pinch analysis for utilities targeting is a well-known deterministic algorithmic procedure that can be translated into a relatively simple linear problem (e.g., with the transshipment model [7]). These targets vary according to the minimal heat recovery approach temperature (HRAT) parameter (also often referred to as $\Delta T \mathrm{Tmin}$ ), which must be carefully chosen by the designer so that heat exchanger areas are not too large, which increases capital costs. A systematic way to choose a value for HRAT involves the minimum area prediction method [3]. The method is illustrated in Figure 1b and involves a heuristic procedure that divides composite curves - which are derived from the application of Pinch analysis - into several enthalpy intervals. Each of these intervals is considered as a single network wherein vertical heat exchange is performed among the streams passing through. A required area value can thus be obtained from these "pseudo" matches. Given the large number of hypothetical matches that can be obtained with this approach, it is often referred to as "spaghetti" design. Linnhoff and Ahmad [3] found that a value for total area can be predicted without effectively sizing each of the heat exchangers in the "spaghetti" design. If cost functions are known for utilities and heat exchange area, one may test different $H R A T$ values for finding one that leads to an optimal trade-off target between capital and operating costs prior to obtaining the HEN design. This may be translated into an NLP problem [8] much simpler than the HEN synthesis problem.

As previously stated, for defining a pressure change route, a superstructure concept comprising a maximum number of passes through a heat recovery region is used. Each of these passes is considered as a stream available for heat exchange. The aforementioned Pinch analysis concepts can be applied to the stream set data, which comprise inlet and outlet temperatures, as well as heat capacity flowrates and heat transfer coefficients. We consider that all pressure change units may be coupled via single-shaft-turbine-compressor (SSTC) units, which is satisfactory for workexchange targeting. 
With those aspects in mind, we can define the decision variables in the present model: those related to the sizing of pressure changers and the HRAT of the heat integration section. Three sets of decision variables are proposed for tackling the problem. All of them use HRAT in the heat recovery part of the model. Differences are in the variables associated to pressure change routes. In the first set, inlet and discharge temperatures for compressors and turbines may vary individually for each unit. In the second set, inlet and discharge temperatures are defined for each stream, instead of unit. That is, all pressure changers of a given stream must operate at the same temperature range. The third set uses one pressure ratio value for all units, but discharge temperatures may vary individually. It is worth noting that, in any case, the derived model is considerably simpler than a simultaneous WHEN model, which should comprise the aforementioned variables associated to pressure changes in addition to all the variables associated to possible stream matching in a HEN.

Note also that these decision variables are pre-defined considering that the solution approach used is a meta-heuristic method. Briefly, the method is programmed to take values for these input variables and sequentially calculate other intermediate variables required for the objective function calculation. The method systematically changes these decision variables seeking for lower-cost solutions. More details on the solution approach are given in Section 2.2.

Besides the described Pinch-based model for optimal pressure change route identification, an additional model is derived here for comparison purposes. It attempts to find a cost-optimal pressure change route considering that all temperature changes are performed by utilities, and includes area and utility costs for heaters and coolers, as well as costs related to pressure changers. The following section describes the mathematical model derived from the superstructure presented in Figure 1a.
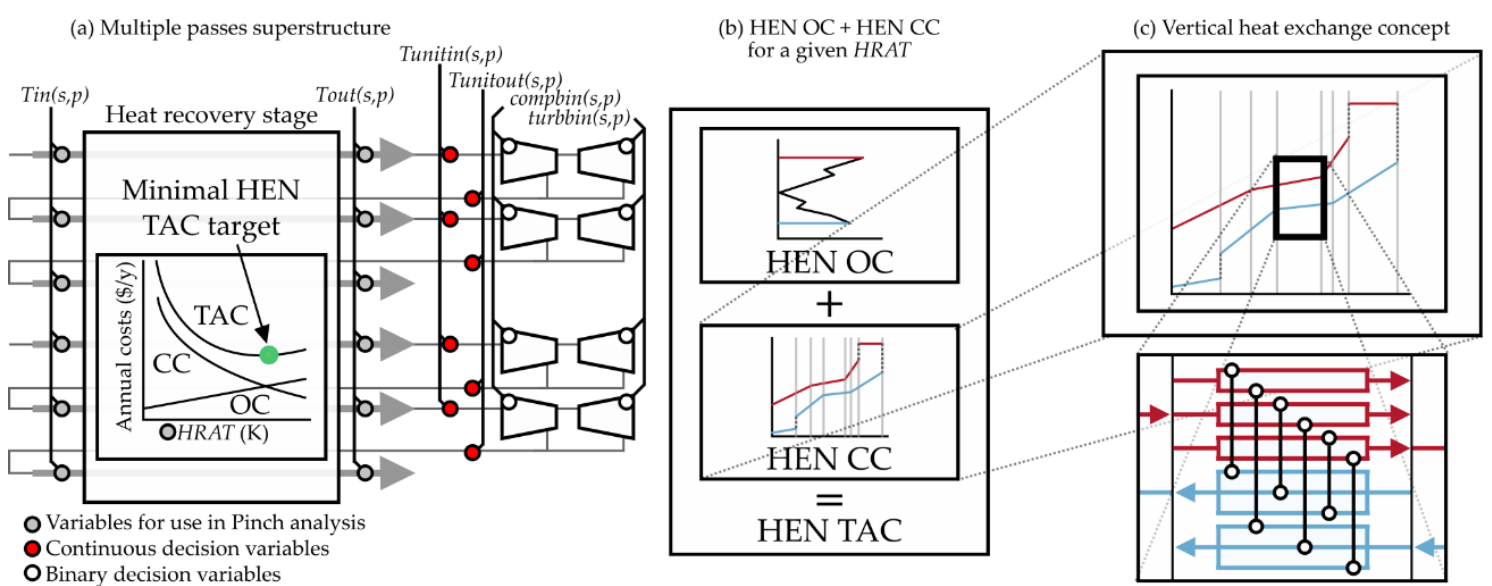

Figure 1. (a) Multi-pass superstructure for WHI, (b) TAC prediction for an HRAT value and (c) Vertical heat exchange for HEN capital costs targeting 


\subsection{Mathematical model}

The equations in the mathematical model are presented here in a sequential order as they are executed by the algorithm when calculating the objective function. The equation set (1)-(12) refers to the modeling used when the algorithm uses individual inlet and discharge temperatures for pressure changer units as decision variables. The $s$ and $p$ indexes concern the streams and their passes through heat recovery stage. Passes are not pre-classified here as hot or cold, which means their classification depends on the values identified for their inlet/outlet temperatures from the heat recovery region.

For all streams, the first pass inlet temperature is assigned with the stream inlet temperature, available from problem data.

$$
\operatorname{Tin}_{s, 1}=\text { Tsupply }_{s}, s \in N S
$$

Analogously, for the first pressure changer (which is placed at the end of the first pass), inlet pressure is assigned with supply pressure from problem data:

$$
\operatorname{pin}_{s, 1}=\operatorname{psupply}_{s}, s \in N S
$$

Pass outlet temperatures from heat recovery stage are assigned with the value attempted by the algorithm for a given pressure change unit.

$$
\text { Tout }_{s, p}=\text { Tunitin }_{s, p}, s \in N S, p \in N P
$$

Inlet temperatures for $p>1$ are assigned with the discharge temperature from the pressure change unit in the previous pass.

$$
\operatorname{Tin}_{s, p}=\text { Tunitout }_{s, p-1}, s \in N S, p \in N P \mid p>1
$$

Similarly, inlet pressures for $p>1$ are assigned as follows:

$$
\operatorname{pin}_{s, p}=\text { pout }_{s, p-1}, s \in N S, p \in N P, p>1
$$

Shaft-work for compressor and turbine units are calculated as follows:

$$
\begin{gathered}
\text { WorkC }_{s, p}=\text { Comp }_{s, p} \cdot C P_{S} \cdot\left(\text { Tunitout }_{s, p}-\text { Tunitin }_{s, p}\right), s \in N S, p \in N P \\
\text { WorkT }_{s, p}=\text { Turb }_{s, p} \cdot C P_{S} \cdot\left(\text { Tunitin }_{s, p}-\text { Tunitout }_{s, p}\right), s \in N S, p \in N P
\end{gathered}
$$

where $\operatorname{Comp}_{s, p}$ and Turb $_{s, p}$ are binary variables denoting existence/absence of a given unit, and $C P_{s}$ is the heat capacity flowrate of a given stream. We ensure that at each pass only a compressor or a turbine exists with the following constraint:

$$
\operatorname{Comp}_{s, p}+\text { Turb }_{s, p} \leq 1, s \in N S, p \in P
$$

Outlet pressure $\left(\right.$ pout $\left._{s, p}\right)$ calculations for these units are performed as follows:

$$
\text { TrevoutC }_{s, p}=\eta_{c} \cdot\left(\text { Tunitout }_{s, p}-\text { Tunitin }_{s, p}\right)+\text { Tunitin }_{s, p}, s \in N S, p \in N P
$$




$$
\begin{gathered}
\text { Trevout }_{s, p}=\text { Tunitin }_{s, p}-\frac{\left(\text { Tunitin }_{s, p}-\text { Tunitout }_{s, p}\right)}{\eta_{t}}, s \in N S, p \in N P \\
\text { Trevout }_{s, p}=\text { Comp }_{s, p} \cdot \text { TrevoutC }_{s, p}+\text { Turb }_{s, p} \cdot \text { Trevout }_{s, p}, s \in N S, p \in N P \\
\text { pout }_{s, p}=\exp \left(\ln \left(\text { pin }_{s, p}\right)-\frac{\kappa}{\kappa-1}\left(\ln \left(\text { Tunitin }_{s, p}\right)-\ln \left(\text { Trevout }_{s, p}\right)\right), s \in N S, p\right. \\
\in N P, p \leq P-2
\end{gathered}
$$

where TrevoutC and Trevout $T$ are discharge temperatures considering reversible compression and expansion processes, $\eta_{c}$ and $\eta_{t}$ are isentropic efficiencies for compressors and turbines and $\kappa$ is the polytropic exponent. Note that these equations are valid for $p<P-2$. That is due to the fact that the two last passes are used for pressure and temperature corrections.

Discharge pressure for $P-1$ is set to the target value provided in the problem data. Therefore, for that pass, pout $t_{s, p}$ is fixed and the equation set (9)-(12) is solved for Tunitin ${ }_{s, p}$. The value for Tunitin $_{s, p}$ is then used to calculate WorkC $_{s, p}$ or $W_{o r k T}$ (Eqs. (6) and (7)) and is assigned to Tout $t_{s, P-}$ $l$ (Eq. (3)).

$$
\text { pout }_{S, P-1}=\text { ptarget }_{S}, s \in N S
$$

This ensures that the discharge pressure always reaches the target value. Note that, for better computing performance, Eqs. (9)-(12) are rearranged in our algorithm for being sequentially solved for Tunitin $_{s, p}$ given pout $t_{s, p}$. This rearrangement is here omitted since they consist on simple algebra steps and the additional equation set would increase the model presentation length.

The unit in $P-1$ may be either a compressor or a turbine depending on its inlet and outlet pressure. This is defined according to the following disjunction:

$$
\left(\begin{array}{c}
\text { out }_{S, P-1}>\text { pout }_{S, P-2} \\
\text { Comp }_{S, P-1}=1 \\
\text { Turb }_{S, P-1}=0
\end{array}\right) \underline{v}\left(\begin{array}{c}
\text { out }_{S, P-1}<\text { pout }_{S, P-2} \\
\text { Comp }_{S, P-1}=0 \\
\text { Turb }_{S, P-1}=1 \\
s \in N S
\end{array}\right) \underline{v}\left(\begin{array}{c}
\text { out }_{S, P-1}=\text { pout }_{S, P-2} \\
\text { Comp }_{S, P-1}=0 \\
\text { Turb }_{S, P-1}=0
\end{array}\right)
$$

For the last stream pass $(p=P)$, we simply assume that the outlet temperature from the heat recovery region is equal to the stream target temperature, provided in the problem data:

$$
\text { Tout }_{s, P}=\text { Ttarget }_{S}, s \in N S
$$

It should be noted that this last pass may either receive or provide heat depending on its inlet temperature $\left(\operatorname{Tin}_{s, P}\right)$.

In case that the algorithm is set to use constant pressure ratio and individual discharge temperatures as decision variables, pout $_{s, p}$ is assigned as follows:

$$
\begin{gathered}
\text { pout }_{s, p}=\operatorname{Comp}_{s, p} \cdot\left(\frac{\text { pin }_{s, p}}{\text { PRatio }_{S}}\right)+\operatorname{Turb}_{s, p} \cdot\left(\text { pin }_{s, p} \cdot \text { PRatio }_{s}\right), s \in N S, p \in N P, p \\
\leq P-2
\end{gathered}
$$


Note that pressure ratio $\left(\right.$ PRatio $\left._{s}\right)$ is defined differently for compressors and turbines. That is assumed here in order for it to range only up to the value of 1.0. That makes this variable simpler to handle by the algorithm. Moreover, in this case, equation set (9)-(12) is solved for Tunitin $_{s, p}$ given pout $_{s, p}$ for all pressure changers. For the pressure changer in $P-2$, discharge pressure is set as the target value. Hence, only in that unit the pressure ratio may differ from PRatios.

As mentioned, pressure ratio upper bound is set as one, while the lower bound for it is obtained as follows for low-pressure streams having only compressors:

$$
\text { PRatioLB }_{S}=\left(\frac{\text { psupply }_{s}}{\text { ptarget }_{s}}\right)^{\frac{1}{\sum_{p \in N P} \text { Comp }_{s, p}}}, s \in N L P S
$$

and for high-pressure streams having only turbines:

$$
\text { PRatioLB }_{s}=\left(\frac{\text { ptarget }_{s}}{\text { psupply }_{s}}\right)^{\frac{1}{\sum_{p \in N P \text { Turb }_{s, p}}}}, s \in \text { NHPS }
$$

In case that constant temperature ranges for pressure changers of each stream are set as decision

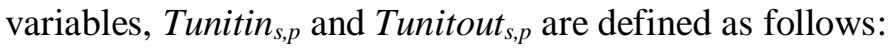

$$
\begin{aligned}
& \text { Tunitin }_{s, p}=\text { AllTunitin }_{s, p}, s \in N S, p \in N P \mid p \leq P-2 \\
& \text { Tunitout }_{s, p}=\text { AllTunitout }_{s}, s \in N S, p \in N P \mid p \leq P-2
\end{aligned}
$$

Note that for $p=P-1$, Tunitin $_{s, p}$ may differ from the pre-defined set according to Eqs. (9)-(12). When optimization is set to perform based either on pressure ratios or general temperature ranges, we set, for simplicity, all pressure changers in HP streams to be turbines, and all pressure changers in LP streams to be compressors.

$$
\begin{aligned}
& \sum_{p \in N P} \operatorname{Turb}_{s, p}=0, s \in N L P S \\
& \sum_{p \in N P} \operatorname{Comp}_{s, p}=0, s \in N H P S
\end{aligned}
$$

Having calculated shaft-works for pressure changers, it is possible to apply the capital cost functions for those units:

$$
\begin{aligned}
\text { TotalCompCosts } & =\sum_{s \in N S} \sum_{p \in N P} \operatorname{Ccomp} \cdot\left(\text { Work }_{s, p}\right)^{\beta \operatorname{comp}} \\
\text { TotalTurbCosts } & =\sum_{s \in N S} \sum_{p \in N P} \operatorname{Cturb} \cdot\left(\text { Work }_{s, p}\right)^{\beta t u r b}
\end{aligned}
$$


Given that coupled compressors and turbines might require auxiliary shaft-work, or may produce a shaft-work surplus, an auxiliary motor or generator might be required, whose capital costs are obtained as follows:

$$
\begin{aligned}
& \text { AuxMCosts }=\max \left(0, \text { Cmot } \cdot\left(\sum_{s \in N S} \sum_{p \in N P} \text { Work }_{s, p}-\sum_{s \in N S} \sum_{p \in N P} \text { WorkT }_{s, p}\right)^{\beta m o t}\right) \\
& \text { AuxGCosts }=\max \left(0, \text { Cgen } \cdot\left(\sum_{s \in N S} \sum_{p \in N P} \text { WorkT }_{s, p}-\sum_{s \in N S} \sum_{p \in N P} \text { WorkC }_{s, p}\right)^{\beta g e n}\right)
\end{aligned}
$$

As previously stated, the model may either consider heat recovery by means of Pinch concepts or simply consider all temperature changes via heaters or coolers. In that latter case, Eqs. (27)-(36) are considered. A disjunction is used to classify the unit prior to a pressure changer as a heater or cooler using the binary variables $\mathrm{Heat}_{s, p}$ and $\mathrm{Cool}_{s, p}$.

$$
\begin{gathered}
\left(\begin{array}{c}
\text { CP }_{S}\left(\text { Tin }_{s, p}-\text { Tout }_{s, p}\right)>Q \min \\
\text { Heat }_{s, p}=1 \\
\text { Cool }_{s, p}=0
\end{array}\right) \underline{\mathrm{v}} \\
\left(\begin{array}{c}
C P_{S}\left(\text { Tin }_{s, p}-\text { Tout }_{s, p}\right)<-Q \min \\
\text { Heat }_{s, p}=0 \\
\text { Cool }_{s, p}=1
\end{array}\right) \underline{\mathrm{v}} \\
\left(\begin{array}{c}
\text { abs }\left(\text { CP }_{S}\left(\text { Tin }_{s, p}-\text { Tout }_{s, p}\right)\right)<Q \min \\
\text { Heat }_{s, p}=0 \\
\text { Cool }_{s, p}=0
\end{array}\right), s \in N S, p \in N P
\end{gathered}
$$

Then, areas for those units are calculated as follows:

$$
\begin{aligned}
& U h u_{s}=\frac{1}{\frac{1}{h_{s}}+\frac{1}{h h u}}, s \in N S \\
& U c u_{s}=\frac{1}{\frac{1}{h_{s}}+\frac{1}{h c u}}, s \in N S
\end{aligned}
$$

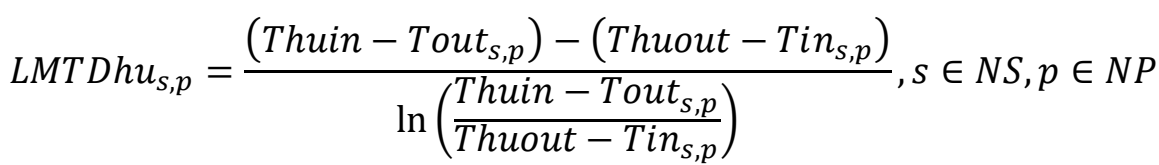

$$
\begin{aligned}
& L M T D c u_{s, p}=\frac{\left(\text { Tin }_{s, p}-\text { Tcuout }\right)-\left(\text { Tout }_{s, p}-\text { Tcuin }\right)}{\ln \left(\frac{\text { Tin }_{s, p}-\text { Tcuout }_{\text {Tout }}-\text { Tcuin }}{\text { Tout }_{s}}\right)}, s \in N S, p \in N P
\end{aligned}
$$




$$
\begin{aligned}
& A h u_{s, p}=\text { Heat }_{s, p} \cdot \frac{C P_{s}\left(\text { Tout }_{s, p}-\text { Tin }_{s, p}\right)}{U h u_{s} \cdot L M T D h u_{s, p}}, s \in N S, p \in N P \\
& A c u_{s, p}=\text { Cool }_{s, p} \cdot \frac{C P_{S}\left(\text { Tin }_{s, p}-\text { Tout }_{s, p}\right)}{U c u_{s} \cdot L M T D C u_{s, p}}, s \in N S, p \in N P
\end{aligned}
$$

where the suffixes $h u$ and $c u$ concern heaters and coolers, being used in overall heat transfer coefficients $\left(U h u_{s}\right.$ and $U c u_{s}$ ), utility heat transfer coefficients ( $h h u$ and $\left.h c u\right)$, logarithmic mean temperature differences $\left(L M T D h u_{s, p}\right.$ and $\left.L M T D c u_{s, p}\right)$ and areas $\left(A h u_{s, p}\right.$ and $\left.A c u_{s, p}\right)$. The parameter $h_{s}$ is the heat transfer coefficient for a given stream $s$. It is worth noting that in case that approach temperature is equal for both heat exchanger ends, the LMTD calculation cannot be computed (division by zero). In that case, a condition statement is implemented in the algorithm so that LMTD operations simply return that approach temperature value (to which, in fact, the LMTD tends in that case). Moreover, the exchanger minimal approach temperature (EMAT) constraint is set to a small value $(1.0 \mathrm{~K})$ so that the algorithm may automatically find optimal approach temperatures.

Capital costs related to heat exchanger areas can be then calculated as follows:

$$
\text { TotalAreaCosts }=\sum_{s \in N S} \sum_{p \in N P} B+C \cdot\left(A h u_{s, p}\right)^{\beta}+\sum_{s \in N S} \sum_{p \in N P} B+C \cdot\left(A c u_{s, p}\right)^{\beta}
$$

For later calculating utility-related operating costs, the following equations are used for obtaining total energy requirements in hot and cold utilities:

$$
\begin{aligned}
& \text { TotalCU }=\sum_{s \in N S} \sum_{p \in N P} \operatorname{Cool}_{s, p} \cdot C P_{S}\left(\text { Tin }_{s, p}-\text { Tout }_{s, p}\right) \\
& \text { TotalHU }=\sum_{s \in N S} \sum_{p \in N P} \text { Heat }_{s, p} \cdot C P_{S}\left(\text { Tout }_{s, p}-\text { Tin }_{s, p}\right)
\end{aligned}
$$

In case that heat recovery is considered via the previously described Pinch concepts, functions implemented in the algorithm are executed and return values for minimum total energy required hot and cold utilities, as well as total capital costs for minimum area, given a set of hot and cold streams, with known heat capacity flowrates, heat transfer coefficients, minimum approach temperature and capital cost functions. Pinch analysis is a classical approach and the implementation of these methodologies has been widely discussed in the literature. For Pinch basics, the reader is referred to original publications of Linnhoff and co-workers [1-3] and to the key book by Kemp [6]. For mathematical programming implementations of the utility and area targeting methods, the reader is referred to the works of Papoulias and Grossmann [7] and Colberg 
and Morari [8]. The previously referred extensive review by Klemeš and Kravanja [4] is also an important support material on the matter. In the present model, we illustrate Pinch-based operations as functions in the equations that follow:

$$
\begin{gathered}
\text { TotalHU }=\text { PinchTotalHU(Tin, Tout, } C P, H R A T) \\
\text { TotalCU }=\text { PinchTotalCU(Tin, Tout, } C P, H R A T)
\end{gathered}
$$

TotalAreaCosts $=$ PinchAreaCosts (Tin, Tout, CP, HRAT, EMAT, h, hcu, hhu)

Note that EMAT and HRAT differ in the sense that the former concerns individual heat exchanger units while the latter regards the approach of heat recovery curves in Pinch Analysis. There are cases that HRAT may be violated by utilities when these are considered in composite curves, but these units may not violate EMAT. Hence, in general, HRAT $\geq E M A T$. In this model, HRAT is a decision variable to be optimized, while EMAT is a parameter that is set with the value of $1.0 \mathrm{~K}$. Finally, total annual costs (TAC) can be calculated as follows:

$$
\begin{aligned}
& T A C= \text { CUCosts } \cdot \text { TotalCU }+ \text { HUCosts } \cdot \text { TotalHU }+ \\
& \max {\left[\text { ELCosts } \cdot\left(\sum_{p \in N P} \sum_{s \in N S} \text { WorkC }_{s, p}-\sum_{p \in N P} \sum_{s \in N S} \text { WorkT }_{s, p}\right), 0\right]-} \\
& \max {\left[\text { ELRev } \cdot\left(\sum_{p \in N P} \sum_{s \in N S} \text { WorkT }_{s, p}-\sum_{p \in N P} \sum_{s \in N S} \text { Work }_{s, p}\right), 0\right]+} \\
& A F \cdot\left(\begin{array}{c}
\text { TotalAreaCosts }+ \text { TotalCompCosts }+ \text { TotalTurbCosts }+ \\
\text { AuxMCosts }+ \text { AuxGCosts }
\end{array}\right.
\end{aligned}
$$

The model for TAC minimization can be written in the following generic form:

$$
\begin{array}{cc}
\text { min } & \{T A C\} \\
\text { s.t. } & \text { Decision variable setup }(i, \text { ii or iii) } \\
& \text { Pressure change equations } \\
& \text { Temperature change equations (Pinch or No Pinch) } \\
& \text { Cost-related equations }
\end{array}
$$

where some aspects may be defined prior to running the model, which affect the set of equations that is used. The decision variable setup concerns what are the variables being manipulated by the optimization approach: (i) individual inlet/discharge temperatures for each unit; (ii) inlet/discharge temperatures for each stream; (iii) pressure ratios for each stream and discharge temperature for each unit. Pressure change equations are those related to the energy balances and sizing of compressors/turbines. Temperature change equations may consider or not heat integration aspects via Pinch. Cost-related equations are those related to operating and capital cost calculations. 


\subsection{Solution approach}

The solution method used here is a hybrid meta-heuristic method. It is illustrated in Figure 2. The algorithm uses Simulated Annealing (SA) [37] and Particle Swarm Optimization (PSO) [38] concepts. Simulated Annealing is used for adding or removing compression/expansion stages, which implies adding/removing passes through the heat integration section of the superstructure.

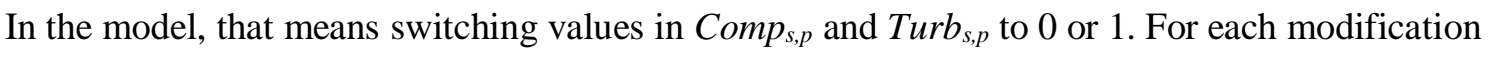
at a given stream, the modified PSO algorithm is applied optimizing continuous decision variable values seeking for minimum TAC. For each pass configuration proposed by SA, PSO is applied five times independently with randomly generated solutions for a greater chance of success. An application of PSO to pressure change routes defined for a stream set is illustrated in Figure 3. Evidently, these random solutions are generated with temperatures/pressure ratios within upper and lower bounds. In the cases approached in this work, compressors are assumed as able to operate from $288 \mathrm{~K}$ to $450 \mathrm{~K}$, and turbines from $288 \mathrm{~K}$ to $800 \mathrm{~K}$. Pressure ratios are generated between PRatioLB (see Eqs. (17) and (18)) and 1.0. The best solution found in these five PSO runs is then stored and placed in the initial swarm of a new PSO application round, which is repeated another five times. The best solution found is then returned and SA decides if it is accepted or not. Note that SA has a chance of accepting worse solutions than the present one, which is efficient for escaping local minima stagnation. The probability of acceptance is defined by a "temperature" parameter. In this work, parameter tuning for SA and PSO is performed based on authors' experience from previous works using SA- and PSO-based approaches. Detailed descriptions of these parameters as well as specific information on SA and PSO mechanisms may be found in those works (e.g., Refs. [39,40]).

An outline of the pressure route optimization experiments to be conducted are provided in Figure 4. Tests may be classified regarding what costs are considered in the objective function (operating only or operating plus capital costs) and regarding the consideration or not of heat integration via Pinch-based model. If no heat integration is assumed, all heating/cooling is performed by means of external utilities. A summary of the cases and their respective codes are as follows:

- Operating and capital costs with heat integration (Case 1 - Main case - CC-HI);

- Operating and capital costs with no heat integration (Case 2 - CC-NoHI);

- Only operating costs with heat integration (Case 3 - NoCC-HI);

- Only operating costs with no heat integration (Case 4 - NoCC-NoHI);

The main methodology proposed here consists of applying Case 1 prior to detailed WHEN design. That is, the Pinch-based model for WHEN targeting considering capital and operating costs. Cases 2, 3 and 4 have an illustrative purpose. It is expected that distinct pressure manipulation routes are obtained from the consideration of different criteria in the objective function. These 
differences may be interesting to observe, and we therefore solve one of the examples in this work considering all these cases.

For a given case, five tests are performed in parallel for each of the three sets of decision variables. Hence, fifteen solutions are obtained in this stage. The best solution found among these fifteen is used as initial solution for five more parallel optimization rounds using individual temperatures as decision variables (Test 4 of Figure 4). Among these new five solutions, the best one is selected and undergoes a refining stage. That is, it is included in the first random swarm for an extensive application of PSO (Test 5 of Figure 4). In that stage, PSO is re-applied 1000 times. The best solution of each application is transferred to the initial random swarm of the next one.

As shown in Figure 4, pressure manipulation routes obtained from cases where capital costs are considered (cases 1 and 2) are used for further detailed HI (Test 6) with the simultaneous HEN synthesis model [30] and for WHI (Test 7) with the simultaneous WHEN synthesis framework [29]. More details on the conduction of the tests are provided in each tackled Example.

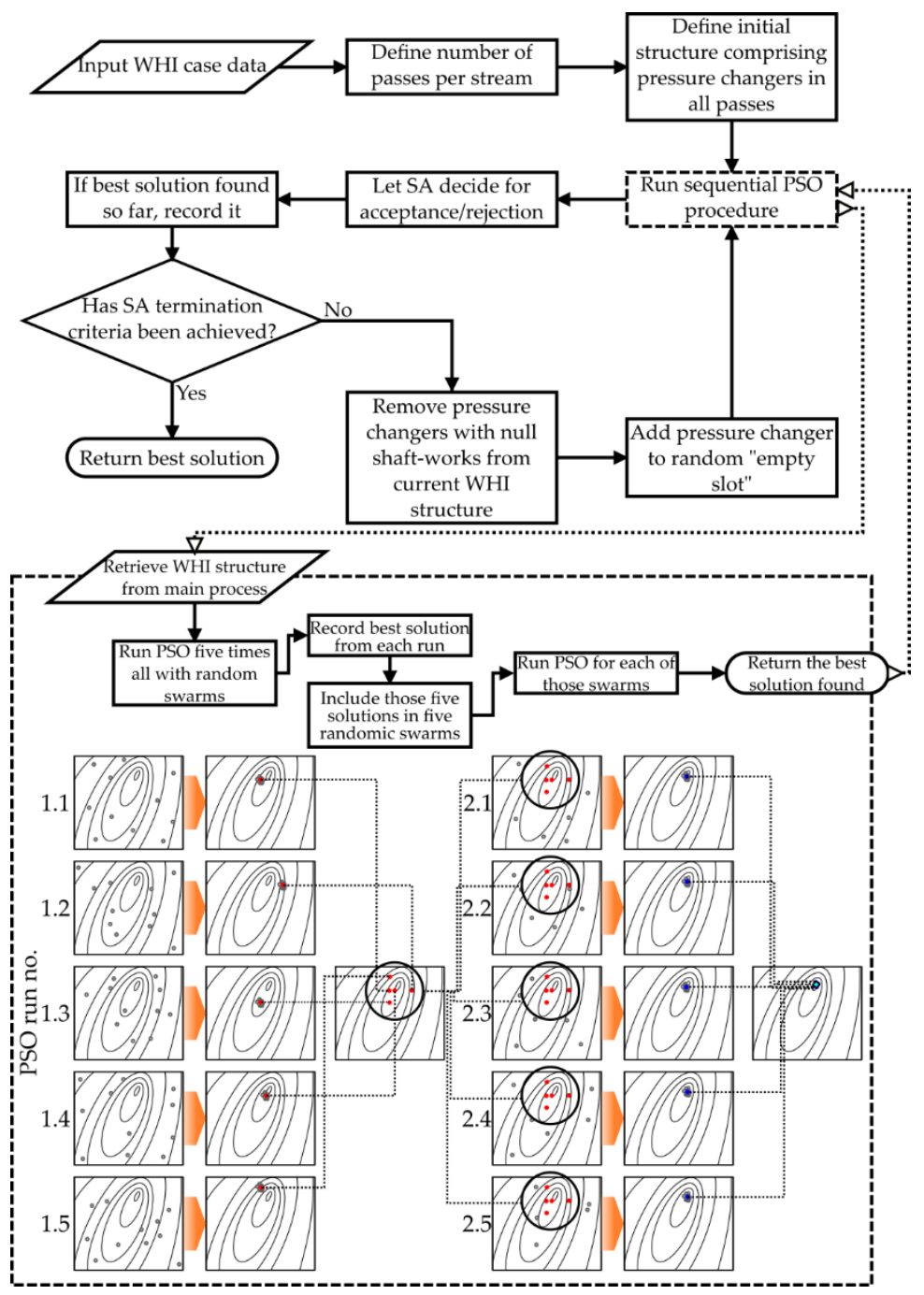

Figure 2. Flow diagram for the hybrid meta-heuristic procedure 

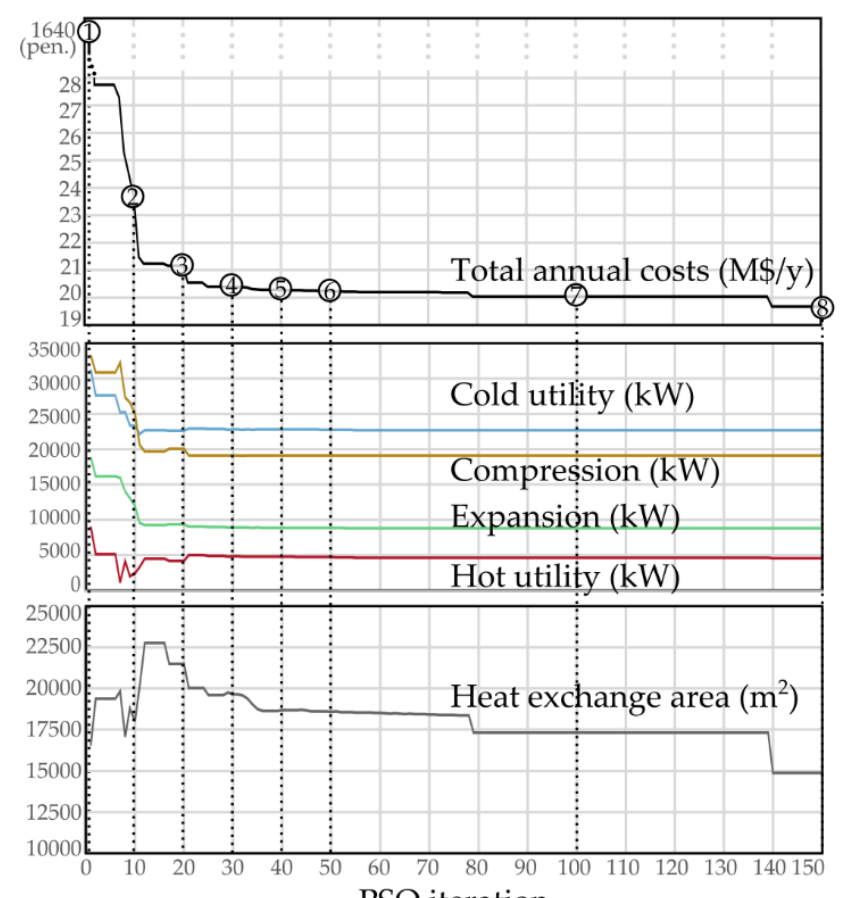

PSO iteration
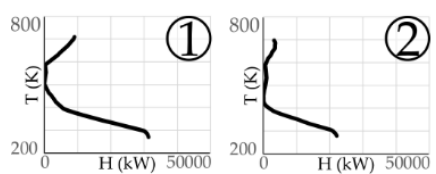

$2)^{800}$

(3)
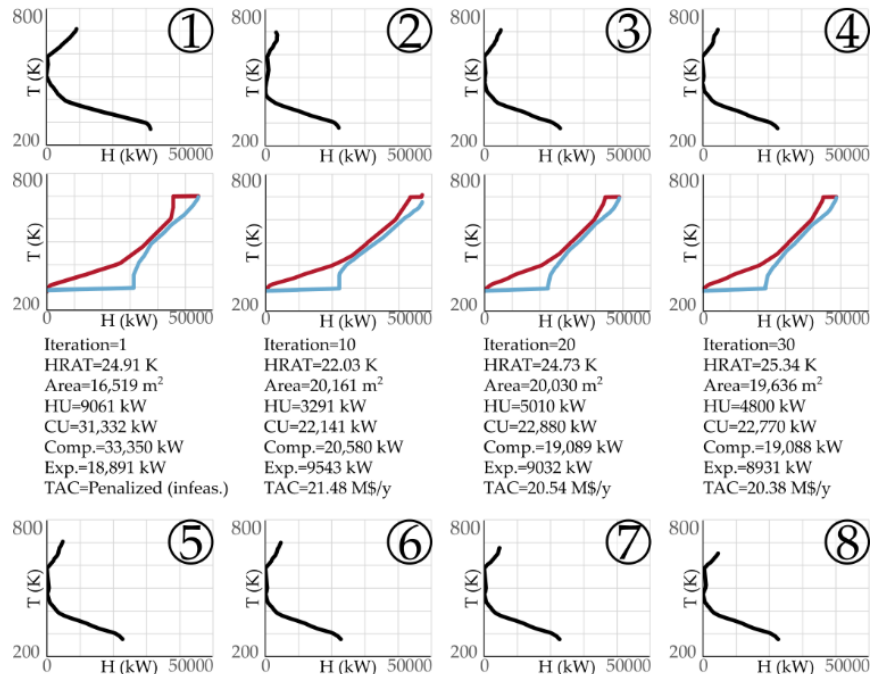

6
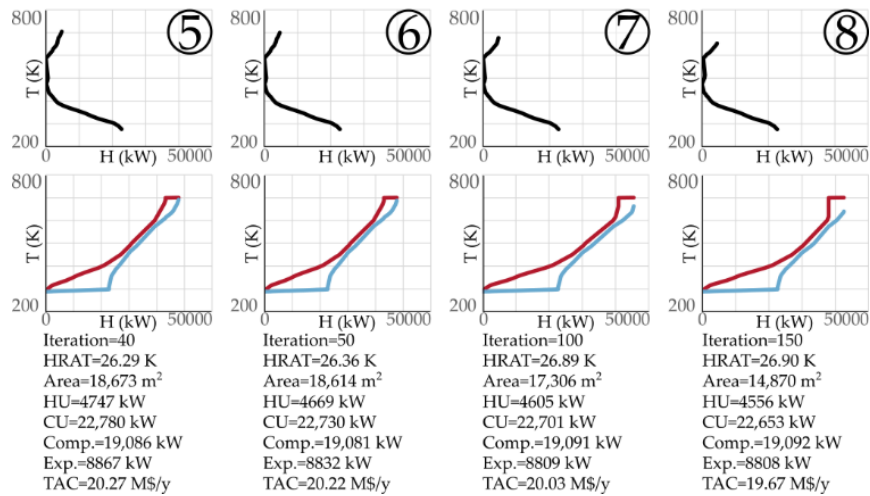

Figure 3. PSO application to a stream set with pressure change route structures defined by SA 


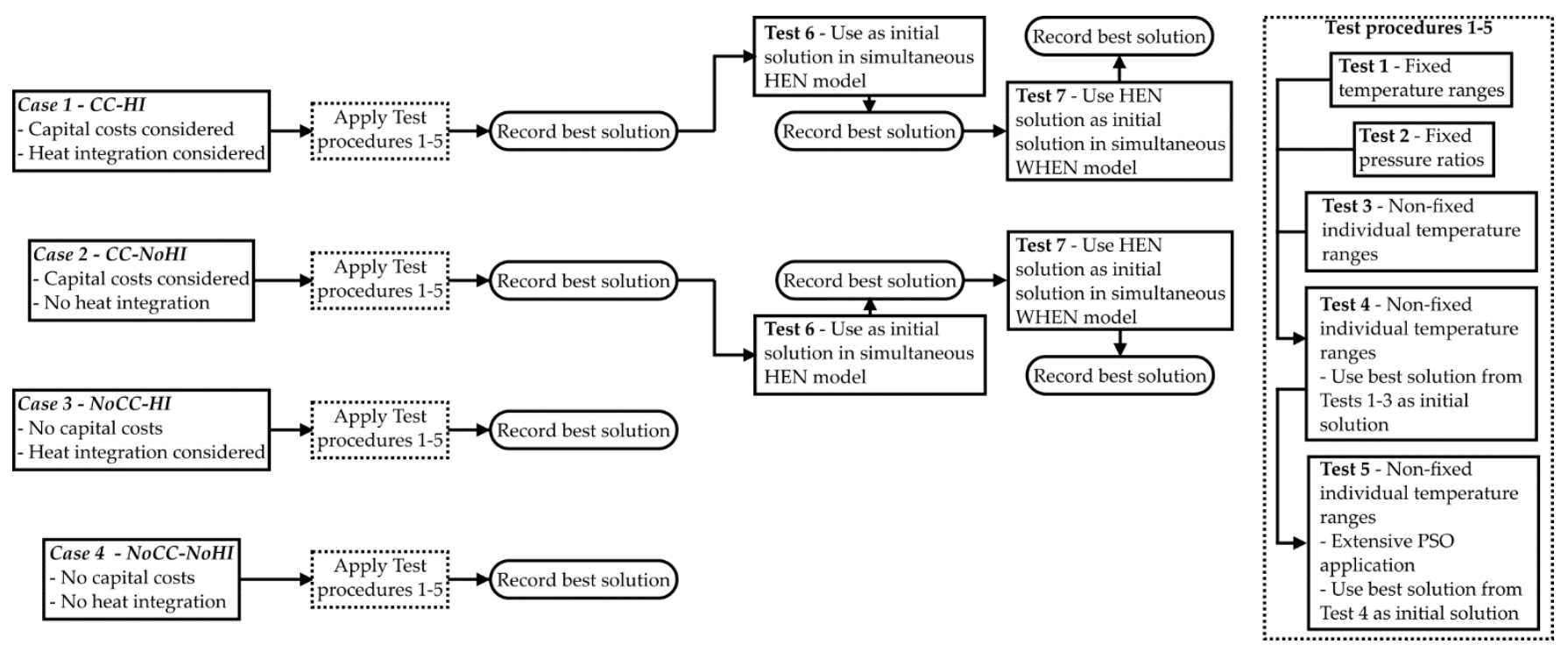

Figure 4. Experiment to be performed in case studies

\section{Numerical Examples}

In this section, two examples are used to verify the method applicability. The formulation used for calculating capital costs (CC) is presented in Table 1. It is similar to that used in Refs. [29,31], except for the heat exchanger CC function, which, for simplicity, is used here in a linearized version rather than the second order polynomial approximations from the referred works. Note that both aforementioned approximations are for the heat exchanger cost prediction method proposed by Turton et al. [41], which involves logarithmic terms. Both second order polynomial and linear approximations are satisfactory and render R-squared values of 0.997 and 0.994 , respectively. The algorithm was coded in Microsoft Visual Studio 2019 using C++ language. All tests were run on a computer with an Intel ${ }^{\circledR}$ Core $^{\mathrm{TM}}$ i7-8750H CPU @ $2.20 \mathrm{GHz}$ and $8.00 \mathrm{~GB}$ of RAM.

Table 1. Capital cost functions for different units

\begin{tabular}{ll}
\hline Unit & Cost function \\
\hline HE $(\$)$ & $71,337.07+747.9931$ (Area) \\
Compressor $(\$)$ & $51,104.85(\text { Work })^{0.62}$ \\
SSTC compressor (\$) & $51,104.85(\text { Work })^{0.62}-985.47(\text { Work })^{0.62}$ \\
Turbine (\$) & $2585.47(\text { Work })^{0.81}$ \\
SSTC turbine (\$) & $2585.47(\text { Work })^{0.81}-985.47(\text { Work })^{0.62}$ \\
Auxiliary motor/generator $(\$)$ & $985.47(\text { Work })^{0.62}$ \\
\hline
\end{tabular}

\subsection{Example 1}

Process streams for this example were based on example 3 from the work of Onishi et al. [24]. Two high ant two low-pressure streams are available. LP streams have target temperatures lower than supply ones, whereas for HP streams, target temperatures are greater than supply ones. Process data is shown in Table 2. Given the wide temperature operating ranges in process streams, correct utility handling is essential in this case. It is thus expected that the employment of a Pinch- 
based methodology defines pressure change routes with efficient heat exchange potential with proper power/utility use. Moreover, it is interesting to note that at such high temperature ranges, it can be expected that LP streams require cooling for lowering power required by compressors, which renders interesting heat transfer possibilities.

The problem is tackled with the four cases proposed in Section 2.2. In the main case (Case $1-$ CC-HI) the employment of the Tunitin/Tunitout/HRAT set of decision variables led to the best results considering the Pinch-based heat integration and its capital costs. The re-optimization tests (4 and 5) did not considerably improve that solution. The TAC predicted by the model considering operating and capital costs is of $16,970,439 \$ / y$. The pressure change routes identified in Tests 1 5 are then transferred as process streams into the heat integration model [30]. The detailed heat integration by means of that model led to a HEN with TAC of $17,053,924 \$ / y$, which is considerably close to the predicted value. The detailed HI solution is then transferred as initial solution into the WHI model [29], which marginally changes heat loads, stream split fractions and shaft-works in the solution, and slightly improves TAC to $17,053,724 \$ / y$. The small difference of only $0.49 \%$ in comparison to the value estimated in the Pinch-based model corroborates the idea of using the presented model prior to the application of HI/WHI models. Grand and hot/cold composite curves for that solution are presented in Figure 5a and b. A notable feature of the solution is the small requirement of hot utilities (which is more expensive in this example) versus cold utilities. The pressure change routes proposed render a HI problem with six hot streams and seven cold streams. Note that stream HEN-C1 (Figure 5c) has the same target and supply temperature. Therefore, in the HI model, its heat requirement is equal to zero, and therefore it is never used. However, in the WHI model, heat exchange could happen on that stream freely, which would alter the first expander inlet temperature. The same situation can be observed in stream HEN-C3. The algorithm found optimal routes considering Pinch-based heat exchange having two pressure changers for streams 1, 2 and 4, and three for stream 3 . Figure $5 \mathrm{~d}$ presents the final detailed WHEN identified with the WHI model.

In Case 2, capital costs are considered, but no heat integration (CC-NoHI). That means all heating/cooling is performed via external utilities and yearly capital costs are added to the objective function. In Case 3, capital costs are not considered, but Pinch-based heat integration is considered with HRAT $=10 \mathrm{~K}(\mathrm{NoCC}-\mathrm{HI})$. In Case 4, neither capital costs nor heat integration are considered (NoCC-NoHI). That means heating and cooling are performed via external utilities, but the optimization aims to minimize operating costs only, neglecting capital costs. Table 3 presents best, worst and average value for the objective function obtained in each case. Average times for the algorithm stagnation are presented as well.

Detailed results for the best optimization run of each case are presented in Table 4. Figure 6 presents pressure change routes for cases 2-4. The final WHEN found in Case 2 (CC-NoHI) has TAC 1.3\% higher than in Case 1. Moreover, the TAC drops between Tests 5, 6 and 7 are much 
more prominent in Case 2 (CC-NoHI) than in Case 1 (CC-HI). This shows that the pressure change routes found in Tests 1-5 in the CC-HI case are more likely to be close to the detailed WHEN routes. In Case 2 these routes may yet change considerably in the detailed HEN and WHEN stages (Tests 6 and 7). This could be expected since the Pinch-based model (Case 1) attempts to predict capital and operating costs of a work-and-heat-integrated system, while Tests 1-5 in Case 2 render utility-only systems.

It can be noted that NoCC-HI and NoCC-NoHI solutions have the greater number of pressure changers: four, which is the preset maximum. That is simply because compression/expansion with intermediate cooling/heating leads to less/more power required/generated. Since power is more expensive than utilities, the algorithm naturally favors utilities use, reducing power requirement. As observed in Table 4, however, this may lead to a large investment, and validates the idea of using an objective function that comprises both capital and operating costs. Another point worth noting is that when heat integration is not considered, expander inlet temperatures are higher than when heat integration is assumed. That is because without heat integration, increasing these temperatures leads to greater power generation, while in the heat integration scenario lowering these temperatures allow more matches to be thermodynamically viable. It is also evident that due to capital investments, the number of units is considerably reduced when $\mathrm{CC}$ is considered. Finally, it must be noted that the illustrative cases (2-4) served the important function of better putting into perspective the methodology proposed in this work (Case 1- CC-HI).

Table 2. Stream data for Example 1

\begin{tabular}{|c|c|c|c|c|c|c|c|}
\hline Stream & Type & Tsupply (K) & Ttarget (K) & $\begin{array}{l}\text { psupply } \\
\text { (MPa) }\end{array}$ & $\begin{array}{l}\text { ptarget } \\
\text { (MPa) }\end{array}$ & $\mathrm{CP}(\mathrm{kW} / \mathrm{K})$ & $\begin{array}{l}\mathrm{h} \quad\left(\mathrm{kW} /\left(\mathrm{m}^{2} \cdot\right.\right. \\
\mathrm{K}))\end{array}$ \\
\hline 1 & LP/Hot & 600 & 350 & 0.1 & 0.7 & 21.480 & 0.1 \\
\hline 2 & LP/Hot & 600 & 360 & 0.1 & 0.9 & 44.172 & 0.1 \\
\hline 3 & HP/Cold & 410 & 600 & 0.9 & 0.1 & 29.448 & 0.1 \\
\hline \multirow[t]{3}{*}{4} & HP/Cold & 355 & 500 & 0.85 & 0.15 & 17.676 & 0.1 \\
\hline & $\mathrm{HU}$ & 700 & 699 & - & - & - & 1.0 \\
\hline & $\mathrm{CU}$ & 288 & 298 & - & - & - & 1.0 \\
\hline \multicolumn{8}{|c|}{ ELCosts $=455.04 \$ / \mathrm{kWy} ;$ ELRev $=400 \$ / \mathrm{kWy} ;$ HUCosts $=337 \$ / \mathrm{kWy} ;$ CUCosts $=100 \$ / \mathrm{kWy}$} \\
\hline \multicolumn{8}{|c|}{ TcompUB $=450 \mathrm{~K} ;$ TcompLB $=288 \mathrm{~K} ;$ TturbUB $=800 ;$ TturbLB $=288 \mathrm{~K}$} \\
\hline \multicolumn{8}{|c|}{$\eta_{c}=\eta_{t}=0.7 ; \kappa=1.4 ; \mu=1.961 \mathrm{~K} / \mathrm{MPa} ; A F=0.18$} \\
\hline
\end{tabular}

Table 3. Detailed results for all tests applied to Example 1

\begin{tabular}{|c|c|c|c|c|c|}
\hline \multirow[b]{2}{*}{ Case } & \multirow[b]{2}{*}{ Decision Variables } & \multicolumn{3}{|l|}{ Obj fun $(\$ / y)$} & \multirow[b]{2}{*}{ Avg. Time (s) } \\
\hline & & Best & Worst & Average & \\
\hline \multicolumn{6}{|c|}{$1-\mathrm{CC}-\mathrm{HI}$} \\
\hline Test 1 & AllTunitin/AllTunitout/HRAT & $17,026,693$ & $17,041,460$ & $17,033,550$ & 905.63 \\
\hline
\end{tabular}




\begin{tabular}{|c|c|c|c|c|c|}
\hline Test 2 & Tunitin/PRatio/HRAT & $17,662,590$ & $17,684,219$ & $17,674,051$ & 733.42 \\
\hline Test 3 & Tunitin/Tunitout/HRAT & $16,970,439$ & $16,987,856$ & $16,980,607$ & 605.93 \\
\hline Test 4 & Tunitin/Tunitout/HRAT & $16,970,439$ & $16,970,439$ & $16,970,439$ & 586.73 \\
\hline Test 5 & Tunitin/Tunitout/HRAT & $16,970,439$ & $16,970,439$ & $16,970,439$ & 167.80 \\
\hline Test 6 & HEN-related & $17,053,924$ & $17,103,366$ & $17,073,983$ & 2173.69 \\
\hline Test 7 & WHEN-related & $17,053,724$ & $17,053,764$ & $17,053,744$ & 4023.61 \\
\hline \multicolumn{6}{|c|}{2 - CC-NoHI } \\
\hline Test 1 & AllTunitin/AllTunitout & $22,832,896$ & $22,832,896$ & $22,832,896$ & 284.05 \\
\hline Test 2 & Tunitin/PRatio & $23,396,883$ & $23,396,884$ & $23,396,883$ & 285.65 \\
\hline Test 3 & Tunitin/Tunitout & $22,807,123$ & $22,807,124$ & $22,807,124$ & 176.29 \\
\hline Test 4 & Tunitin/Tunitout & $22,807,124$ & $22,807,124$ & $22,807,124$ & 152.76 \\
\hline Test 5 & Tunitin/Tunitout & $22,807,124$ & $22,807,124$ & $22,807,124$ & 25.52 \\
\hline Test 6 & HEN-related & $18,785,837$ & $18,834,251$ & $18,796,124$ & 2713.86 \\
\hline Test 7 & WHEN-related & $17,267,908$ & $17,337,443$ & $17,297,239$ & 3020.91 \\
\hline \multicolumn{6}{|c|}{3 - NoCC-HI } \\
\hline Test 1 & AllTunitin/AllTunitout & $6,408,849$ & $6,508,627$ & $6,442,210$ & 1160.93 \\
\hline Test 2 & Tunitin/PRatio & $6,162,659$ & $6,222,485$ & $6,192,104$ & 1309.57 \\
\hline Test 3 & Tunitin/Tunitout & $6,207,858$ & $6,296,313$ & $6,246,482$ & 1337.85 \\
\hline Test 4 & Tunitin/Tunitout & $6,162,659$ & $6,162,659$ & $6,162,659$ & 1249.22 \\
\hline Test 5 & Tunitin/Tunitout & $6,162,659$ & $6,162,659$ & $6,162,659$ & 603.38 \\
\hline \multicolumn{6}{|c|}{4 - NoCC-NoHI } \\
\hline Test 1 & AllTunitin/AllTunitout & $12,832,241$ & $12,832,241$ & $12,832,241$ & 78.75 \\
\hline Test 2 & Tunitin/PRatio & $12,756,634$ & $12,757,729$ & $12,756,879$ & 231.63 \\
\hline Test 3 & Tunitin/Tunitout & $12,758,733$ & $12,827,444$ & $12,777,949$ & 376.22 \\
\hline Test 4 & Tunitin/Tunitout & $12,756,618$ & $12,756,631$ & $12,756,628$ & 261.86 \\
\hline Test 5 & Tunitin/Tunitout & $12,756,617$ & $12,756,617$ & $12,756,617$ & 250.57 \\
\hline
\end{tabular}

Table 4. Design aspects for Example 1 solutions

\begin{tabular}{llllllllll}
\hline & Obj. Fun. $(\$ / \mathrm{y})$ & OC $(\$ / \mathrm{y})$ & $\mathrm{CC}(\$ / \mathrm{y})$ & Area $\left(\mathrm{m}^{2}\right)$ & $\mathrm{HU}(\mathrm{kW})$ & $\mathrm{CU}(\mathrm{kW})$ & Comp $(\mathrm{kW})$ & Exp $(\mathrm{kW})$ & HRAT $(\mathrm{K})$ \\
\hline CC-HI & $16,970,439$ & $7,597,384$ & $9,373,055$ & $11,945.81$ & 386.95 & $20,175.75$ & $19,369.85$ & $7,394.19$ & 13.14 \\
Detailed HI from CC-HI & $17,053,924$ & $7,595,145$ & $9,458,779$ & $12,105.65$ & 381.82 & $20,170.63$ & $19,369.85$ & $7,394.19$ & - \\
Detailed WHI from CC-HI & $17,053,724$ & $7,595,701$ & $9,458,023$ & $12,098.79$ & 384.94 & $20,172.29$ & $19,370.21$ & $7,395.99$ & - \\
CC-NoHI & $22,807,124$ & $14,008,887$ & $8,798,237$ & $7,737.74$ & $17,147.79$ & $35,291.70$ & $19,320.42$ & $8,989.65$ & - \\
Detailed HI from CC-NoHI & $18,450,779$ & $8,870,315$ & $9,580,464$ & $13,166.07$ & $5,389.04$ & $23,532.95$ & $19,320.42$ & $8,989.65$ & - \\
Detailed WHI from CC-NoHI & $17,267,908$ & $7,980,940$ & $9,286,968$ & $12,089.27$ & 714.44 & $20,936.45$ & $19,347.61$ & $6,938.74$ & - \\
NoCC-HI & $6,162,658$ & $6,162,658$ & $15,377,162$ & $43,006.40$ & 294.48 & $17,571.19$ & $17,685.50$ & $8,221.93$ & 10 \\
NoCC-NoHI & $12,756,616$ & $12,756,616$ & $13,262,493$ & $21,665.74$ & $20,069.27$ & $33,656.83$ & $17,685.55$ & $11,911.13$ & - \\
\hline
\end{tabular}


(a) Grand composite curve

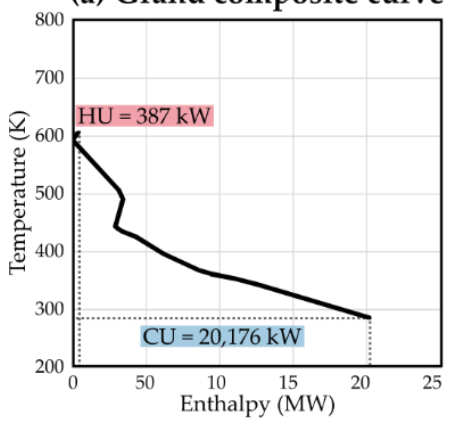

(c) Pressure change routes (b) Hot/cold composite curves

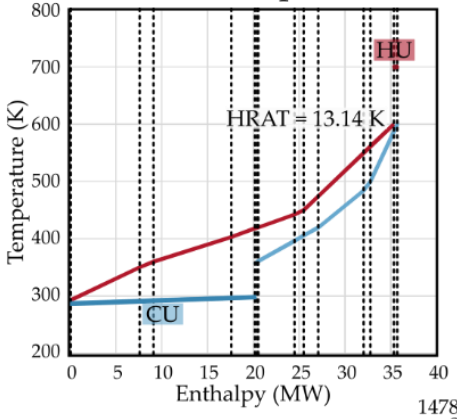

(d) Detailed WHEN

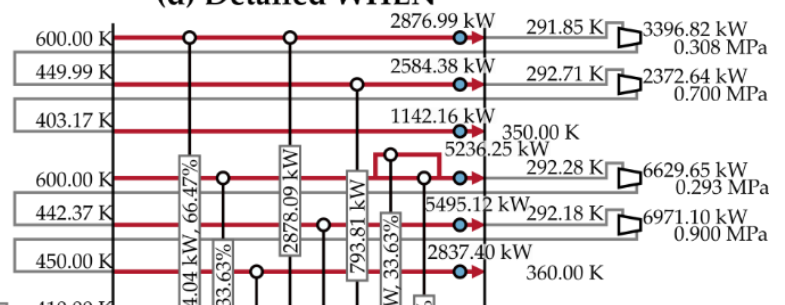

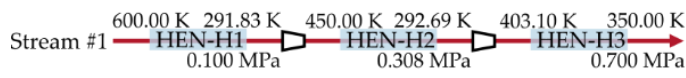

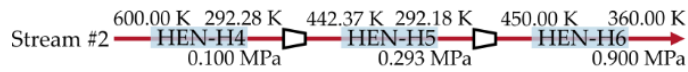

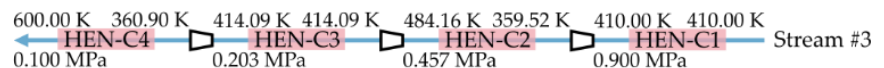

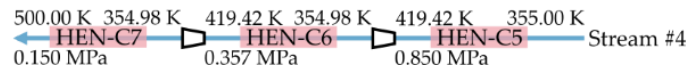

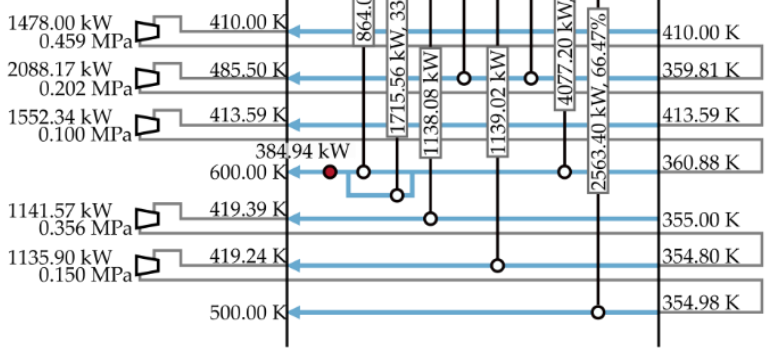

Figure 5. Summary of results obtained for Example 1

Case 2 - Capital costs considered but no heat integration (CC-NoHI)

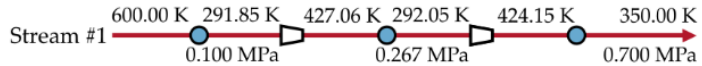

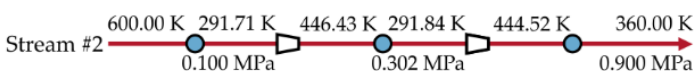

$$
\begin{aligned}
& \underset{0.100 \mathrm{MPa}}{600.00 \mathrm{~K}} \mathrm{O}_{0.900 \mathrm{MPa}}^{423.92 \mathrm{~K}} \mathrm{C}^{629.29 \mathrm{~K}}{ }^{410.00 \mathrm{~K}} \text { Stream } \# 3
\end{aligned}
$$

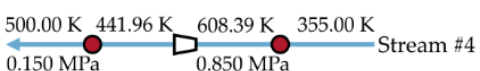

Case 3 - No capital costs considered, heat integration considered (NoCC-HI)

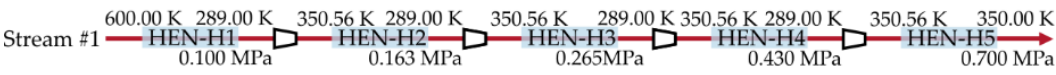

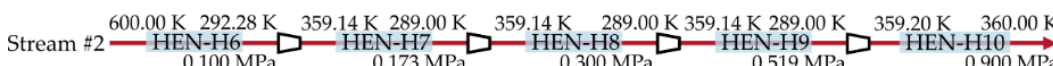

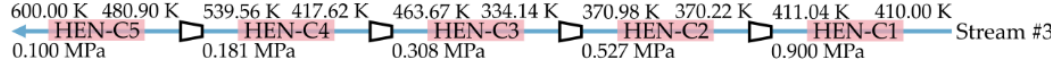

$$
\begin{aligned}
& 500.00 \mathrm{~K} \quad 541.87 \mathrm{~K} \quad 590.00 \mathrm{~K} 541.87 \mathrm{~K} \quad 590.00 \mathrm{~K} \quad 382.30 \mathrm{~K} \quad 416.25 \mathrm{~K} \quad 350.97 \mathrm{~K} \quad 381.49 \mathrm{~K} \quad 355.00 \mathrm{~K}
\end{aligned}
$$

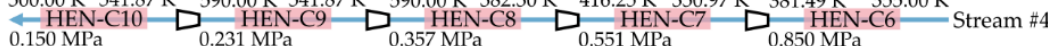

Case 4 - No capital costs and no heat integration (NoCC-NoHI)

$$
\text { Stream \#1 }
$$

Figure 6. Pressure change routes obtained with different considerations in the objective function

\subsection{Example 2}

This is a practical example based on the membrane separation processes of $\mathrm{CO}_{2}$ and $\mathrm{N}_{2}$ in postcombustion carbon capture. Fu and Gundersen [28] modeled a membrane separation process 
configuration proposed by Zhao et al. [42] as a WHI problem. They considered one of the retentate streams for heat exchange with a flue gas and an air stream. Pavão et al. [29] extended the case study to include all permeate and retentate streams into the WHI procedure. Data as in Ref. [29] is presented in Table 5. Note that no hot utilities are available in the WHI modeling. Here, we assume a hypothetical hot utility during optimization runs $(650 \mathrm{~K}-649 \mathrm{~K}$, HUCosts $=400 \$ / \mathrm{kW})$. A characteristic of this example is that the two $\mathrm{N}_{2}$ retentate streams are released into the atmosphere. That is, there is no target temperature set for those streams. Hence, they are treated as two additional decision variables in our model.

Table 5. Stream data for Example 2

\begin{tabular}{llllllll}
\hline Stream & Type & Tsupply $(\mathrm{K})$ & Ttarget $(\mathrm{K})$ & $\begin{array}{l}\text { psupply } \\
(\mathrm{MPa})\end{array}$ & $\begin{array}{l}\text { ptarget } \\
(\mathrm{MPa})\end{array}$ & $\mathrm{CP}(\mathrm{kW} / \mathrm{K})$ & $\begin{array}{l}\mathrm{h}\left(\mathrm{kW} /\left(\mathrm{m}^{2} \cdot\right.\right. \\
\mathrm{K}))\end{array}$ \\
\hline 1 & LP & 298.15 & 298.15 & 0.1 & 0.8 & 37.49 & 0.1 \\
2 & LP & 298.15 & 298.15 & 0.1 & 0.8 & 10.09 & 0.1 \\
3 & Hot & 650.15 & 348.15 & - & - & 43.77 & 0.1 \\
4 & HP & 298.15 & - & 0.8 & 0.1 & 27.40 & 0.1 \\
5 & HP & 298.15 & - & 0.8 & 0.1 & 4.40 & 0.1 \\
6 & Cold & 288.15 & 600.15 & - & - & 34.7 & 0.1 \\
& CU & 288.15 & 289.15 & - & - & - & 1.0 \\
\hline
\end{tabular}

ELCosts $=455.04 \$ / \mathrm{kWy} ;$ ELRev $=364.03 \$ / \mathrm{kWy} ;$ CUCosts $=100 \$ / \mathrm{kWy} ;$

TcompUB $=450 \mathrm{~K} ;$ TcompLB $=288 \mathrm{~K} ;$ TturbUB $=800 ;$ TturbLB $=288 \mathrm{~K}$;

$\eta_{c}=0.85 ; \eta_{t}=0.9 ; \kappa=1.4 ; \mu=1.961 \mathrm{~K} / \mathrm{MPa} ; A F=0.18$

This example is tackled considering the main case (Case 1 - CC-HI). The Pinch-based model (Tests 1-5) identified a solution with cold utilities only, as in Refs. [28,29]. It is worth noting in the composite curves (Figure 7) that the ideal placement for cold utilities is performed at intermediate enthalpy intervals, since there are process streams (from turbine discharges) that operate at lower temperatures than those of the cold utility. In the detailed HEN synthesis test, the cold utility was included in the problem formulation as a process stream with fixed $C P$, and whose associated production costs were those identified in the predicted maximal energy recovery (MER) network. These costs were fixed and always added to the objective function. Stream end utilities also were penalized (their operating costs were multiplied by 100). Those measures (fixing total cold utility costs and penalizing hot utility costs) are taken to enforce the algorithm to evolve the network towards a structure with no heaters/coolers at stream ends, which means that a MER network with only cold utilities is found.

Even with that approach, there is a chance that the algorithm may get trapped in local minima solutions which have hot utilities or stream end utilities. Therefore, we conduct optimization runs of the HEN detailed model test considering as starting point (i) the "trivial" solution (i.e., a 
solution that achieves target temperatures using only stream end utilities) and (ii) a so-called "spaghetti" solution [3]. The "spaghetti" solution (as referred to by Linnhoff and co-workers) is a solution with extensive vertical heat exchange, and that generally comprises a large number of heat exchangers. The network is divided into the same number of stages as the number of enthalpy intervals in the composite curve, with supply and target temperatures as in the referred curve as well. Each stage is then considered as an individual network, and need to have their energy needs fulfilled. We can easily find a spaghetti solution by individually synthesizing each of these networks and then merging these results into one structure. This is performed here with the employment of the $\mathrm{HI}$ framework [30] to each stage in isolation. Using this procedure with the composite curve from Figure 7 guarantees that we begin the detailed HEN test with a minimum energy requirement network, with no utilities at stream ends. Figure 8 presents the "spaghetti" HEN solution used. Table 6 shows test results. The best solution identified using the spaghetti configuration as starting point has TAC slightly lower than that obtained from employing the trivial one as starting point. Moreover, considering all the five runs for each of the starting points, those from the spaghetti solution led to solutions with 54,693 \$/y (0.64\%) lower TAC in average than with the trivial solution at the detailed HI stage. The detailed WHI stage is then conducted with the detailed HI solution as initial configuration, but a marginal improvement is achieved. The relative difference between the TAC obtained for the detailed WHEN versus that predicted with the Pinch-based model is of $1.2 \%$, indicating that prediction by Pinch-based model is quite accurate.

As previously stated, capital costs for heat exchangers are calculated from a linearized version of the function used in Refs. [29,31]. For comparison, if the solution found here is re-evaluated with the original second order polynomial from those works, TAC would be 8,618,533 $\$ / y$. That value is $0.9 \%$ lower than that associated to the solution found with our simultaneous model $(8,695,841$ $\$ / y$ ) [29]. This demonstrates that the determination of pressure change routes a priori via Pinchbased concepts considering capital and operating costs may lead to better WHEN results than with the heuristically determined routes used in that work.

Table 6. Design aspects for Example 2 solutions

\begin{tabular}{|c|c|c|c|c|c|c|c|c|c|}
\hline & $\begin{array}{ll}\text { Obj. } & \text { Fun. } \\
(\$ / y) & \end{array}$ & OC (\$/y) & $\mathrm{CC}(\$ / y)$ & $\begin{array}{l}\text { Area } \\
\left(\mathrm{m}^{2}\right)\end{array}$ & $\begin{array}{l}\mathrm{HU} \\
(\mathrm{kW})\end{array}$ & $\begin{array}{l}\mathrm{CU} \\
(\mathrm{kW})\end{array}$ & $\begin{array}{l}\text { Comp } \\
(\mathrm{kW})\end{array}$ & $\begin{array}{l}\text { Exp } \\
(\mathrm{kW})\end{array}$ & $\begin{array}{l}\text { HRAT } \\
(\mathrm{K})\end{array}$ \\
\hline CC-HI & $8,388,513$ & $\begin{array}{l}3,186,16 \\
6\end{array}$ & $\begin{array}{l}5,202,34 \\
6\end{array}$ & $9,412.76$ & 0.00 & $4,132.72$ & $10,056.53$ & $3,962.79$ & - \\
\hline Detailed spaghetti network & $8,863,595$ & $\begin{array}{l}3,186,16 \\
6\end{array}$ & $\begin{array}{l}5,677,42 \\
9\end{array}$ & $9,412.59$ & 0.00 & $4,132.72$ & $10,056.53$ & $3,962.79$ & - \\
\hline $\begin{array}{llll}\text { Detailed HI } & \text { (from "spaghetti" } \\
\text { network) } & & & \end{array}$ & $8,490,827$ & $\begin{array}{l}3,186,16 \\
6\end{array}$ & $\begin{array}{l}5,304,66 \\
0\end{array}$ & $9,695.82$ & 0.00 & $4,132.72$ & $10,056.53$ & $3,962.79$ & - \\
\hline Detailed HI (from trivial network) & $8,510,027$ & $\begin{array}{l}3,186,16 \\
6\end{array}$ & $\begin{array}{l}5,323,86 \\
0\end{array}$ & $\begin{array}{l}10,029.1 \\
7\end{array}$ & 0.00 & $4,132.72$ & $10,056.53$ & $3,962.79$ & - \\
\hline Detailed WHI & $8,490,819$ & $\begin{array}{l}3,186,17 \\
2\end{array}$ & $\begin{array}{l}5,304,64 \\
7\end{array}$ & $9,695.72$ & 0.00 & $4,132.72$ & $10,056.53$ & $3,962.78$ & - \\
\hline
\end{tabular}


(a) Grand composite curve

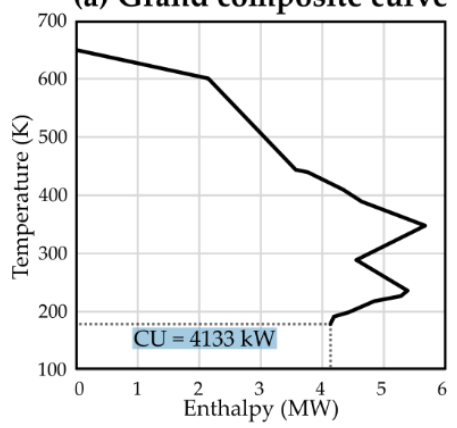

(c) Pressure change routes

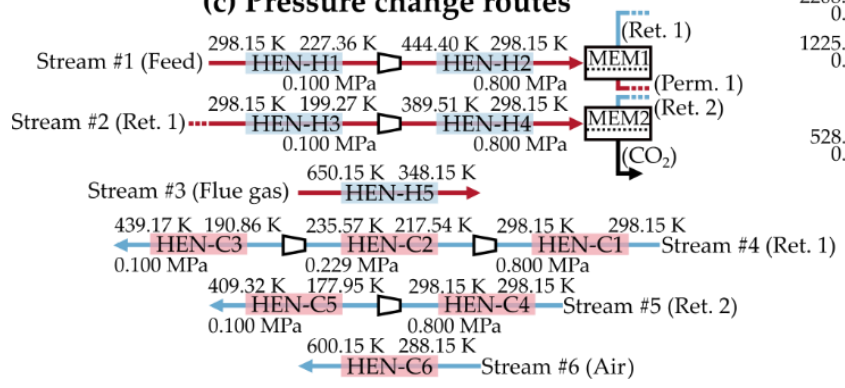

Figure 7. Summary of results obtained for Example 2 (d) Detailed WHEN
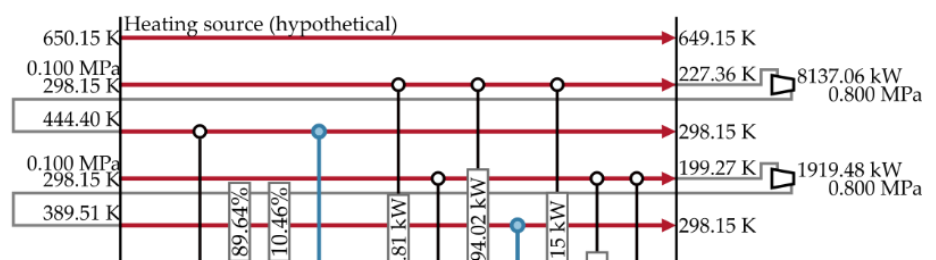

$650.15 \mathrm{~K} \longrightarrow 0$

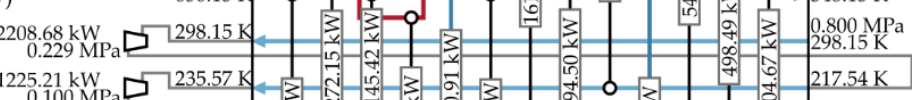

$25.21 \mathrm{~kW}$

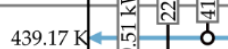

$28.89 \mathrm{~kW}$
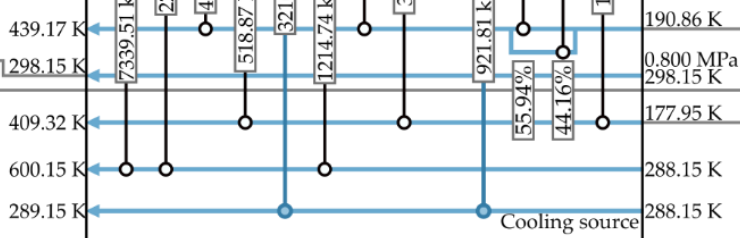

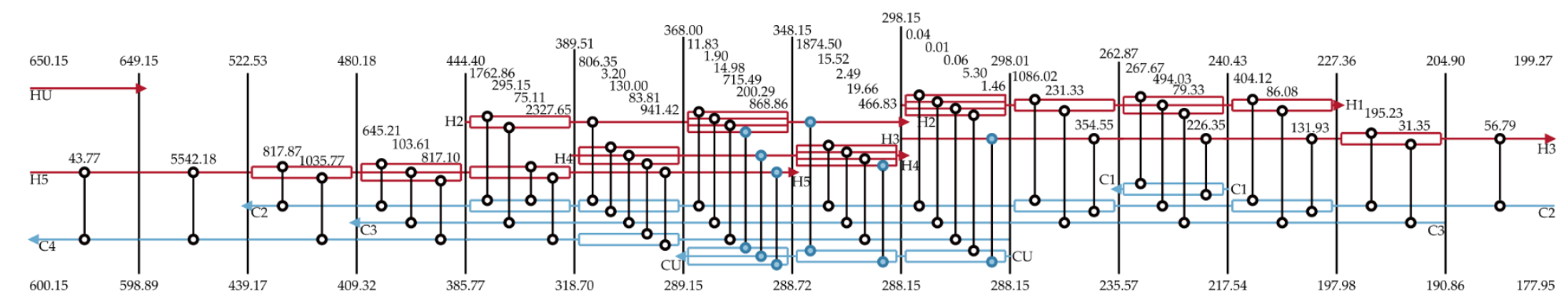

Figure 8. "Spaghetti” solution to Example 2 HI stage

\section{Conclusions}

A Pinch-based strategy for defining pressure manipulation routes in work and heat exchange networks was presented in this work. An advantage of the method is the possibility of considering heat integration targets during pressure changers optimization, providing a reasonable prediction for total annual costs prior to the detailed HEN and WHEN synthesis (i.e., match allocations, heat exchangers sizing). Hence, the proposed model provides a systematic way of defining pressure changer routes based on capital and operating costs. The method was applied to two examples. It has been shown that TAC targets found with the targeting model are accurate in comparison to final optimized designs ( $0.5 \%$ and $1.2 \%$ differences in examples 1 and 2). Moreover, example 2 results demonstrated that the predicted route configurations served as efficient starting points for WHEN synthesis given that results achieved when using them were less expensive than when using trivial solutions as initial solutions. The complexity of simultaneous WHEN synthesis models hampers the development of derived models considering, for instance, multiple objectives or uncertain parameters. A simplified model such as that presented in this work is easier to solve 
in comparison to those considering heat exchanger matches simultaneously to pressure change routes. Thus, it may enable these considerations to be implemented in future works.

\section{Acknowledgements}

The authors gratefully acknowledge the financial support from the Coordination for the Improvement of Higher Education Personnel - Processes 88887.360812/2019-00 and 88881.171419/2018-01 - CAPES (Brazil) and the National Council for Scientific and Technological Development - Processes 305055/2017-8 and 311807/2018-6 - CNPq (Brazil).

\section{Nomenclature}

Variables

Acu

Cooler area $\left[\mathrm{m}^{2}\right]$

Ahu Heater area $\left[\mathrm{m}^{2}\right]$

AllTunitin

Inlet temperature for all pressure changers in a given stream $[\mathrm{K}]$

AllTunitout Outlet temperature for all pressure changers in a given stream $[\mathrm{K}]$

AuxGCosts Auxiliary generator cost $[\$ / y]$

AuxMCosts Auxiliary motor cost $[\$ / y]$

Comp

Binary variable denoting compressor existence/absence [-]

Cool

Binary variable denoting cooler existence/absence [-]

Heat

Binary variable denoting heater existence/absence [-]

LMTDcu

Logarithmic mean temperature difference for coolers $[\mathrm{K}]$

LMTDhu

Logarithmic mean temperature difference for heaters $[\mathrm{K}]$

pin

Inlet pressure in a pressure changer [MPa]

pout

Outlet pressure in a pressure changer [MPa]

PRatio

Pressure ratio [-]

TAC

Total annual costs [\$/y]

Tin

Stream pass inlet temperature [K]

TotalAreaCosts

Total area annual costs $[\$ / y]$

TotalCompCosts

Total compressor costs $[\$ / y]$

TotalCU

Total cold utility requirement $[\mathrm{kW}]$

TotalHU

Total hot utility requirement $[\mathrm{kW}]$

TotalTurbCosts

Tout

Total turbine costs $[\$ / y]$

Trevout

Stream pass outlet temperature $[\mathrm{K}]$

TrevoutC

Outlet temperature for a pressure changer considering a reversible process $[\mathrm{K}]$

TrevoutT

Outlet temperature for a compressor considering a reversible process [K]

Tunitin

Outlet temperature for a turbine considering a reversible process [K]

Tunitout

Pressure changer inlet temperature [K]

Turb

Pressure changer outlet temperature $[\mathrm{K}]$

Ucu

Binary variable denoting turbine existence/absense [-]

Uhu

Overall heat transfer coefficient for a cooler $\left[\mathrm{kW} / \mathrm{m}^{2} \mathrm{~K}\right]$

Overall heat transfer coefficient for a heater $\left[\mathrm{kW} / \mathrm{m}^{2} \mathrm{~K}\right]$ 


\begin{tabular}{|c|c|}
\hline WorkC & Shaft-work rate in a compressor $[\mathrm{kW}]$ \\
\hline WorkT & Shaft-work rate in a turbine $[\mathrm{kW}]$ \\
\hline \multicolumn{2}{|l|}{ Parameters } \\
\hline$A F$ & Annualization factor $\left[\mathrm{y}^{-1}\right]$ \\
\hline$B$ & Heat exchanger fixed cost $[\$ / y]$ \\
\hline$C$ & Heat exchanger capital cost factor $\left[\$ / \mathrm{m}^{2 \beta} \mathrm{y}\right]$ \\
\hline Ccomp & Compressor capital cost factor $\left[\$ / \mathrm{kW}^{\beta} \mathrm{y}\right]$ \\
\hline Cgen & Auxiliary generator capital cost factor $\left[\$ / \mathrm{kW}^{\beta} \mathrm{y}\right]$ \\
\hline Cmot & Auxiliary motor capital cost factor $\left[\$ / \mathrm{kW}^{\beta} \mathrm{y}\right]$ \\
\hline$C P$ & Heat capacity flowrate $[\mathrm{kW} / \mathrm{K}]$ \\
\hline Cturb & Turbine capital cost factor $\left[\$ / \mathrm{kW}^{\beta} \mathrm{y}\right]$ \\
\hline CUCosts & Cold utility costs $[\$ / \mathrm{kWy}]$ \\
\hline ELCosts & Electricity costs $[\$ / \mathrm{kWy}]$ \\
\hline ELRev & Electricity revenue price $[\$ / \mathrm{kWy}]$ \\
\hline EMAT & Exchanger minimal approach temperature $[\mathrm{K}]$ \\
\hline$h$ & Convective heat transfer coefficient for a stream $\left[\mathrm{kW} / \mathrm{m}^{2} \mathrm{~K}\right]$ \\
\hline$h c u$ & Convective heat transfer coefficient for cold utility $\left[\mathrm{kW} / \mathrm{m}^{2} \mathrm{~K}\right]$ \\
\hline$h h u$ & Convective heat transfer coefficient for hot utility $\left[\mathrm{kW} / \mathrm{m}^{2} \mathrm{~K}\right]$ \\
\hline$H R A T$ & Heat recovery approach temperature $[\mathrm{K}]$ \\
\hline HUCosts & Hot utility costs $[\$ / \mathrm{kWy}]$ \\
\hline PRatioLB & Pressure ratio lower bound [-] \\
\hline psupply & Supply pressure $[\mathrm{MPa}]$ \\
\hline ptarget & Target pressure $[\mathrm{MPa}]$ \\
\hline Qmin & Minimum heat load $[\mathrm{kW}]$ \\
\hline TcompLB & Compressor temperature lower bound $[\mathrm{K}]$ \\
\hline TcompUB & Compressor temperature upper bound $[\mathrm{K}]$ \\
\hline Tcuin & Cold utility inlet temperature $[\mathrm{K}]$ \\
\hline Tcuout & Cold utility outlet temperature $[\mathrm{K}]$ \\
\hline Thuin & Hot utility inlet temperature $[\mathrm{K}]$ \\
\hline Thuout & Hot utility outlet temperature $[\mathrm{K}]$ \\
\hline Tsupply & Stream supply temperature $[\mathrm{K}]$ \\
\hline Ttarget & Stream target temperature $[\mathrm{K}]$ \\
\hline TturbLB & Turbine temperature lower bound $[\mathrm{K}]$ \\
\hline TturbUB & Turbine temperature upper bound $[\mathrm{K}]$ \\
\hline \multicolumn{2}{|c|}{ Special characters } \\
\hline$\beta$ & Heat exchanger cost exponent $[-]$ \\
\hline$\beta$ comp & Compressor cost exponent [-] \\
\hline Bgen & Helper generator cost exponent [-] \\
\hline$\beta m o t$ & Helper motor cost exponent [-] \\
\hline$\beta$ turb & Turbine cost exponent [-] \\
\hline$\eta c$ & Isentropic efficiency for compressors [-] \\
\hline
\end{tabular}


$\eta t$

$\kappa$

Subscripts

$p$

$P$

$s$

Sets

NLPS

NHPS

$N P$

NS

Functions

$\max$

PinchTotalCU

PinchTotalHU

PinchAreaCosts

Acronyms

CC

HEN

HP

LP

MER

MINLP

OC

PSO

SA

SSTC

SWS

TAC

WEN

WHEN

WI

WHI
Isentropic efficiency for turbines [-]

Polytropic exponent [-]

Pass index

Last pass index

Stream index

Low-pressure streams set

High-pressure streams set

Stream passes set

Streams set

Function that finds the maximum value within a set

Function that finds cold utility target via Pinch Analysis [kW]

Function that finds hot utility target via Pinch Analysis [kW]

Function that finds minimum area costs via Pinch Analysis [\$/y]

Capital costs

Heat exchanger network

High-pressure

Low-pressure

Maximal energy recovery

Mixed-integer nonlinear programming

Operating costs

Particle swarm optimization

Simulated annealing

Single-shaft-turbine-compressor

Stagewise superstructure

Total annual costs

Work exchange network

Work and heat exchange network

Work integration

Work and heat integration

\section{References}

[1] Linnhoff B, Flower JR. Synthesis of heat exchanger networks: I. Systematic generation of energy optimal networks. AIChE J 1978;24:633-642. doi:10.1002/aic.690240411.

[2] Linnhoff B, Hindmarsh E. The pinch design method for heat exchanger networks. Chem Eng Sci 1983;38:745-63. doi:10.1016/0009-2509(83)80185-7.

[3] Linnhoff B, Ahmad S. Cost optimum heat exchanger networks-1. Minimum energy and 
capital using simple models for capital cost. Comput Chem Eng 1990;14:729-50. doi:10.1016/0098-1354(90)87083-2.

[4] Klemeš JJ, Kravanja Z. Forty years of Heat Integration: Pinch Analysis (PA) and Mathematical Programming (MP). Curr Opin Chem Eng 2013;2:461-74. doi:10.1016/J.COCHE.2013.10.003.

[5] Klemeš JJ, Varbanov PS, Walmsley TG, Jia X. New directions in the implementation of Pinch Methodology (PM). Renew Sustain Energy Rev 2018;98:439-68. doi:10.1016/J.RSER.2018.09.030.

[6] Kemp I. Pinch Analysis and Process Integration. Elsevier Ltd; 2006. doi:10.1016/B9780-7506-8260-2.X5001-9.

[7] Papoulias SA, Grossmann IE. A structural optimization approach in process synthesisII: Heat recovery networks. Comput Chem Eng 1983;7:707-21.

[8] Colberg RD, Morari M. Area and capital cost targets for heat exchanger network synthesis with constrained matches and unequal heat transfer coefficients. Comput Chem Eng 1990;14:1-22. doi:10.1016/0098-1354(90)87002-7.

[9] Floudas CA, Ciric AR, Grossmann IE. Automatic synthesis of optimum heat exchanger network configurations. AIChE J 1986;32:276-90. doi:10.1002/aic.690320215.

[10] Floudas CA, Ciric AR. Strategies for overcoming uncertainties in heat exchanger network synthesis. Comput Chem Eng 1989;13:1133-52.

[11] Yee TF, Grossmann IE. Simultaneous optimization models for heat integration-II. Heat exchanger network synthesis. Comput Chem Eng 1990;14:1165-84. doi:10.1016/00981354(90)85010-8.

[12] Pavão L V, Costa CBB, Ravagnani MASS. A new stage-wise superstructure for heat exchanger network synthesis considering substages, sub-splits and cross flows. Appl Therm Eng 2018;143:719-35.

[13] Nair SK, Karimi IA. Unified Heat Exchanger Network Synthesis via a Stageless Superstructure. Ind Eng Chem Res 2019:acs.iecr.8b04490. doi:10.1021/acs.iecr.8b04490.

[14] Xiao Y, Kayange HA, Cui G, Chen J. Non-structural model of heat exchanger network: Modeling and optimization. Int $\mathrm{J}$ Heat Mass Transf 2019;140:752-66. doi:10.1016/J.IJHEATMASSTRANSFER.2019.06.039.

[15] Andrews WT, Laker DS. A twelve-year history of large scale application of workexchanger energy recovery technology. Desalination 2001;138:201-6. doi:10.1016/S0011-9164(01)00265-X.

[16] Blurton RN, Ruckley LJ. CONSERVATION OF ENERGY ON A 40,000 BPSD FLUID CATALYTIC CRACKING UNIT UTILISING A FLUE GAS EXPANSION TURBINE. Energy Money, Mater. Eng., Elsevier; 1982, p. T2-49-T2-62. doi:10.1016/B978-0-08028774-4.50018-X. 
[17] Huang YL, Fan LT. Analysis of a Work Exchanger Network. Ind Eng Chem Res 1996;35:3538. doi:10.1021/IE9507383.

[18] Cheng C-Y, Cheng S-W, Fan L-T. Flow work exchanger. AIChE J 1967;13:438-42. doi:10.1002/aic.690130310.

[19] Zhuang Y, Liu L, Zhang L, Du J. Upgraded Graphical Method for the Synthesis of Direct Work Exchanger Networks. Ind Eng Chem Res 2017;56:14304-15. doi:10.1021/acs.iecr.7b03319.

[20] Aspelund A, Berstad DO, Gundersen T. An Extended Pinch Analysis and Design procedure utilizing pressure based exergy for subambient cooling. Appl Therm Eng 2007;27:2633-49. doi:10.1016/J.APPLTHERMALENG.2007.04.017.

[21] Wechsung A, Aspelund A, Gundersen T, Barton PI. Synthesis of heat exchanger networks at subambient conditions with compression and expansion of process streams. AIChE J 2011;57:2090-108. doi:10.1002/aic.12412.

[22] Razib MS, Hasan MMF, Karimi IA. Preliminary synthesis of work exchange networks. Comput Chem Eng 2012;37:262-77. doi:10.1016/j.compchemeng.2011.09.007.

[23] Onishi VC, Ravagnani MASS, Caballero JA. Simultaneous synthesis of heat exchanger networks with pressure recovery: Optimal integration between heat and work. AIChE J 2014;60:893-908. doi:10.1002/aic.14314.

[24] Onishi VC, Ravagnani MASS, Caballero JA. Simultaneous synthesis of work exchange networks with heat integration. Chem Eng Sci 2014;112:87-107. doi:10.1016/j.ces.2014.03.018.

[25] Onishi VC, Ravagnani MASS, Caballero JA. Retrofit of heat exchanger networks with pressure recovery of process streams at sub-ambient conditions. Energy Convers Manag 2015;94:377-93. doi:10.1016/j.enconman.2015.02.002.

[26] Huang K, Karimi IA. Work-heat exchanger network synthesis (WHENS). Energy 2016;113:1006-17. doi:10.1016/j.energy.2016.07.124.

[27] Fu C, Gundersen T. Correct integration of compressors and expanders in above ambient heat exchanger networks. Energy 2016;116:1282-93. doi:10.1016/J.ENERGY.2016.05.092.

[28] Fu C, Gundersen T. Heat and work integration: Fundamental insights and applications to carbon dioxide capture processes. Energy Convers Manag 2016;121:36-48. doi:10.1016/J.ENCONMAN.2016.04.108.

[29] Pavão L V., Costa CBB, Ravagnani MASS. A new framework for work and heat exchange network synthesis and optimization. Energy Convers Manag 2019;183:617-32. doi:10.1016/J.ENCONMAN.2019.01.018.

[30] Pavão L V, Costa CBB, Ravagnani MASS. An enhanced stage-wise superstructure for heat exchanger networks synthesis with new options for heaters and coolers placement. 
Ind Eng Chem Res 2018;57:2560-73.

[31] Pavão L V., Costa CBB, Ravagnani MASS. Work and heat exchange network synthesis considering multiple electricity-related scenarios. Energy 2019;182:932-53. doi:10.1016/J.ENERGY.2019.06.079.

[32] Nair SK, Nagesh Rao H, Karimi IA. Framework for work-heat exchange network synthesis (WHENS). AIChE J 2018. doi:10.1002/aic.16129.

[33] Fu C, Vikse M, Gundersen T. Work and heat integration: An emerging research area. Energy 2018;158:796-806. doi:10.1016/J.ENERGY.2018.06.030.

[34] Yu H, Fu C, Vikse M, Gundersen T. Work and heat integration-A new field in process synthesis and process systems engineering. AIChE J 2018:aic.16477. doi:10.1002/aic.16477.

[35] Vikse M, Fu C, Barton PI, Gundersen T. Towards the Use of Mathematical Optimization for Work and Heat Exchange Networks. Chem Eng Trans 2017;61:1351-6. doi:10.3303/CET1761223.

[36] Furman KC, Sahinidis N V. Computational complexity of heat exchanger network synthesis. Comput Chem Eng 2001;25:1371-90.

[37] Kirkpatrick S, Gelatt CD, Vecchi MP. Optimization by simulated annealing. Science 1983;220:671-80. doi:10.1126/science.220.4598.671.

[38] Kennedy J, Eberhart R. Particle swarm optimization. Proc. ICNN'95 - Int. Conf. Neural Networks, vol. 4, IEEE; 1995, p. 1942-8. doi:10.1109/ICNN.1995.488968.

[39] Pavão LV, Costa CBB, Ravagnani MASS. Heat Exchanger Network Synthesis without stream splits using parallelized and simplified simulated Annealing and Particle Swarm Optimization. Chem Eng Sci 2017. doi:10.1016/j.ces.2016.09.030.

[40] Pavão LV, Costa CBB, Ravagnani MASS, Jiménez L. Large-scale heat exchanger networks synthesis using simulated annealing and the novel rocket fireworks optimization. AIChE J 2017;63:1582-601. doi:10.1002/aic.15524.

[41] Turton R, Bailie RC, Whiting WB, Shaeiwitz JA, Bhattacharyya D. Analysis, Synthesis, and Design of Chemical Processes. 4th ed. Ann Arbor, MI, USA: Prentice Hall; 2012.

[42] Zhao L, Riensche E, Blum L, Stolten D. Multi-stage gas separation membrane processes used in post-combustion capture: Energetic and economic analyses. J Memb Sci 2010;359:160-72. doi:10.1016/J.MEMSCI.2010.02.003. 